Kolumnentitel/Kurztitel: SCHOOL LOCKDOWN DURING COVID-19 PANDEMIC

Teaching and Learning During the COVID-19 School Lockdown: Realization and Associations with Parent-Perceived Students' Academic Outcomes-A study and preliminary overview

This version of the manuscript was submitted November, $17^{\text {th }}$, and has not been accepted for publication yet.

\author{
Ricarda Steinmayr ${ }^{\mathrm{a}}$ \\ TU Dortmund University \\ Rebecca Lazarides ${ }^{\mathrm{b}}$ \\ University of Potsdam \\ Anne F. Weidinger ${ }^{\mathrm{c}}$ \\ TU Dortmund University \\ Hanna Christiansen ${ }^{\mathrm{d}}$ \\ Philipps University Marburg
}

aDepartment of Psychology, TU Dortmund University, Emil-Figge-Straße 50, 44227

Dortmund, Germany. E-mail: ricarda.steinmayr@tu-dortmund.de

${ }^{b}$ Department of Education, University of Potsdam, Department of Education, Karl-Liebknecht

Straße 24-25, 14476 Potsdam OT Golm, Germany. E-mail: rebecca.lazarides@unipotsdam.de

${ }^{\mathrm{c}}$ Department of Psychology, TU Dortmund University, Emil-Figge-Straße 50, 44227

Dortmund, Germany.E-mail: anne.weidinger@tu-dortmund.de

${ }^{\mathrm{d}}$ Department of Clinical Child and Adolescent Psychology and Psychotherapy, Philipps

University Marburg, Gutenbergstraße 18, 35032 Marburg, Germany. E-mail:

hanna.christiansen@staff.uni-marburg.de

Correspondence concerning this article should be addressed to Ricarda Steinmayr, Department of Psychology, TU Dortmund University, Emil-Figge-Straße 50, 44227

Dortmund, Germany. Phone: +49 231-755 7118, Fax: +49 231-755 2929, E-mail: ricarda.steinmayr@tu-dortmund.de 
Acknowledgments: We would like to thank Selina Engelhardt and Sven Jansen for their support in creating the online questionnaire and in data collection, and Melda Kavak for proof reading a previous version of this manuscript. Furthermore, we would like to thank all parents who found the time to participate in our study despite homeschooling their kids and their other duties. 
SCHOOL LOCKDOWN DURING COVID-19 PANDEMIC

\title{
Teaching and Learning During the COVID-19 School Lockdown: Realization and Associations with Parent-Perceived Students' Academic Outcomes-A study and preliminary overview
}

\begin{abstract}
Due to the COVID-19 pandemic, all schools in Germany were locked down for several months in 2020. How schools realized teaching during the school lockdown greatly varied from school to school. $N=2647$ parents participated in an online survey and rated the following activities of teachers in mathematics, language art (German), English, and science/biology during the school lockdown: frequency of sending task assignments, task solutions and requesting for solutions, giving task-related feedback, grading tasks, providing lessons per videoconference, and communicating via telecommunication tools with students and/or parents. Parents also reported student academic outcomes during the school lockdown (child's learning motivation, competent and independent learning, learning progress). Parents further reported student characteristics and social background variables: child's negative emotionality, school engagement, mathematical and language competencies, and child's social and cultural capital. Data were separately analyzed for elementary and secondary schools. In both samples, frequency of student-teacher communication was associated with all academic outcomes, except for learning progress in elementary school. Frequency of parentteacher communication was associated with motivation and learning progress, but not with competent and independent learning, in both samples. Other distant teaching activities were differentially related to students' academic outcomes in elementary vs. secondary school. School engagement explained most additional variance in all students' outcomes during the school lockdown. Parent's highest school leaving certificate incrementally predicted students' motivation, and competent and independent learning in secondary school, as well as learning progress in elementary school. The variable "child has own bedroom" additionally explained
\end{abstract}


variance in students' competent and independent learning during the school lockdown in both samples. Thus, both teaching activities during the school lockdown as well as children's characteristics and social background were independently important for students' motivation, competent and independent learning, and learning progress. Results are discussed with regard to their practical implications for realizing distant teaching.

Keywords: COVID-19, distant teaching, teaching quality, motivation, academic competencies 


\section{Zusammenfassung}

Aufgrund der COVID-19-Pandemie waren alle Schulen in Deutschland in 2020 für mehrere Monate geschlossen. Wie die einzelnen Schulen den Fernunterricht realisierten, variierte stark zwischen den Schulen. $N=2647$ Eltern nahmen an einer Online-Befragung teil und schätzten die folgenden Aktivitäten der Mathematik-, Deutsch-, Englisch-, und Sachunterricht/Biologielehrkraft im Fernunterricht ein: Häufigkeit, mit der Aufgaben und Lösungen geschickt, Lösungen des Kindes angefordert, Feedback zu den Lösungen des Kindes gegeben, Aufgaben benotet, Unterricht per Videokonferenz abgehalten und mit dem Kind bzw. den Eltern via Telefon o.Ä. kommuniziert wurde. Außerdem schätzten die Eltern die schulischen Outcomes ihres Kindes während des Fernunterrichts ein (d.h. Motivation, kompetentes und selbstständiges Lernverhalten und den Lernfortschritt). Schließlich machten die Eltern Angaben zu den folgenden Eigenschaften und soziodemografischen Merkmalen ihres Kindes: negative Emotionalität, schulisches Engagement, mathematische und sprachliche Kompetenzen, soziales und kulturelles Kapital. Die Daten wurden separat für Grund- und weiterführenden Schulen ausgewertet. In beiden Stichproben war die Schüler*innenLehrkraft-Kommunikation mit allen Schüler*innenoutcomes assoziiert, außer mit dem Lernfortschritt in der Grundschule. Die Häufigkeit der Eltern-Lehrkraft-Kommunikation war in beiden Stichproben mit der Motivation und dem Lernfortschritt, jedoch nicht mit dem kompetenten und selbstständigen Lernverhalten assoziiert. Die Bedeutung weiterer Lehraktivitäten im Fernunterricht unterschied sich zwischen Grund- und weiterführender Schule. Das schulische Engagement der Kinder erklärte die meiste zusätzliche Varianz in den Schüler*innenoutcomes im Fernunterricht. Der höchste Schulabschluss der Eltern erklärte inkrementell Varianz in der Schüler*innenmotivation und in dem kompetenten und selbstständigen Lernverhalten an der weiterführenden Schule sowie im Lernfortschritt an der Grundschule. Ein eigenes Kinderzimmer erklärte in beiden Stichproben zusätzlich Varianz im kompetenten und selbstständigen Lernverhalten während des Fernunterrichts. Also waren die 
SCHOOL LOCKDOWN DURING COVID-19 PANDEMIC

Lehraktivitäten während des Fernunterrichts, die Eigenschaften der Schüler*innen und der soziale Hintergrund unabhängig voneinander wichtig für Motivation, kompetentes und selbstständiges Lernverhalten und Lernfortschritt während des Fernunterrichts. Die Ergebnisse werden in Bezug auf ihre praktischen Implikationen für die Realisierung von Fernunterricht diskutiert.

Schlagwörter: COVID-19-Pandemie, Fernunterricht, Instruktionsqualität, Motivation, schulische Kompetenzen 
SCHOOL LOCKDOWN DURING COVID-19 PANDEMIC

\section{Teaching and Learning During the COVID-19 School Lockdown: Realization and}

\section{Associations with Parent-Perceived Students' Academic Outcomes-A study and preliminary overview}

The lockdown of all schools due to the COVID-19 pandemic faced students, parents, and teachers with new challenges. Within days, teaching changed from classroom teaching to distant teaching and learning. Given the fact that German schools are still not up to the digital and technical infrastructure common in other countries like the U.S. (e.g., Eickelmann \& Gerrick, 2020), the prerequisites for online teaching via videoconference were not given at most schools (Hoffmann, 2020; Sliwka \& Klopsch, 2020). Furthermore, the Ministries of Education of all federal states completely allocated the realization of distant teaching during the school lockdown to the schools (see also Fickermann \& Edelstein, 2020; Wrase, 2020). Consequently, the way in which distant teaching was realized at each single school greatly varied between schools (see Goldan, Geist \& Lütje-Klose, 2020). Teaching quality is an important prerequisite for students' academic achievement, motivation, and emotion (e.g., Baumert et al., 2010; Klieme, 2020; Lazarides \& Buchholz, 2019; Rabbani, Talepasand, Boogar \& Mohammadifar, 2018). Consequently, different teaching activities during the school lockdown (in the following labeled as 'distant teaching activities') are probably related to students' motivation, learning behaviors and academic achievement when students had to learn at home. To date, just a few studies (e.g., Huber \& Helm, 2020; Porsch \& Porsch, 2020; Thorell et al., under review; Wacker, Unger, \& Rey, 2020; Wildemann \& Hosenfeld, 2020) examined on a descriptive level distant teaching and motivational and academic outcomes of children during the COVID-19 school lockdown. Furthermore, researchers discussed the realization of teaching quality during the school lockdown (Voss \& Wittwer, 2020). Huber and Helm (2020) furthermore investigated relations between distant teaching activities and students' academic outcomes during the school lockdown controlling for socio-demographic variables and students' characteristics. Given the current dearth of literature concerned with 
distant teaching and its academic consequences, there is a high need for further research aiming to extend our understanding of the consequences of the school lockdown, in case the COVID-19 pandemic requires further school lockdowns. The aim of the present article was threefold. First, we provide a preliminary overview on studies investigating the realization of distant teaching activities and student outcomes during the school lockdown. Second, we examine differences in the realization of distant teaching. Third, we investigate how these differences were associated with students' motivation, competent and independent learning, and learning progress during the school lockdown.

\section{Effects of the COVID-19 pandemic-related school lockdown on children and adolescents}

A first study in seven European countries on over 6000 children and adolescents that examined the time of the school lockdown during the COVID-19 pandemic demonstrated that overall parents found distant teaching to be of poor quality, with insufficient support from schools (Thorell et al., under review). Between 19-25\% of the parents in this study reported that successful learning was not possible at home during the school lockdown due to a lack of structured instructions. Most often teachers only sent out material/homework once a week and parents felt on their own with the responsibility to handle instructions. Porsch and Porsch (2020), for example, reported that $48 \%$ of parents had no contact to teachers apart from receiving teaching tasks, and that only $14 \%$ were satisfied with the support received from schools. However, some countries were more advanced than others, for example, in Sweden, over $30 \%$ of the parents stated that their children received schooling in form of live webinars, whereas only $5.16 \%$ of the children in Germany and $4.41 \%$ in the UK received such support (Thorell et al., under review). In a study from Germany, over $50 \%$ of the parents $(N=4230)$ said that their child was not motivated to learn (Wildemann \& Hosenfeld, 2020). Teachers sent feedback in $26 \%$ of the cases - thus the majority of children did not receive any feedback on task assignments. In accordance with such findings, a small study of $N=169$ German students showed that $48 \%$ of the students reported to sometimes get feedback from 


\section{SCHOOL LOCKDOWN DURING COVID-19 PANDEMIC}

their teachers, $20 \%$ never got feedback, and only $19 \%$ stated that they often received teacher feedback (Wacker et al., 2020). A possible explanation might be that teachers felt poorly prepared for distant teaching; previous findings indicated that one-third $(31.9 \%)$ of the mostly German 1059 teachers reported that they did not feel well prepared for distant teaching, whereas only $5.2 \%$ of the teachers reported that they felt prepared (Runge, Rubach \& Lazarides, 2020). In this context, the finding of another study is highly concerning: almost $30 \%$ of participating parents did not see it as their responsibility to motivate their child, and over $20 \%$ also used coercive strategies (Wildemann \& Hosenfeld, 2020). Not surprisingly, parents reported increased levels of stress, worry, social isolation, reduced subjective wellbeing and domestic conflicts and a reduced relationship quality with their child during the school lockdown (Lades, Laffan, Daly, Delaney, 2020; Thorell et al., under review; Wildemann \& Hosenfeld, 2020). Especially parents of children with special needs reported strains (Thorell et al., under review). A positive example of addressing students with special needs is the "Laborschule" that tried to keep up personal contact and regular feedback for students and teachers even though digital infrastructure was also hampered (Goldan et al., 2020).

Summing up, the studies currently available on distant teaching during the school lockdown due to the COVID-19 pandemic demonstrate an overall heterogeneous picture, though a substantial number of teachers did not feel prepared for the situation whereas students and parents did not evaluate distant teaching positively and reported negative impacts on their own and their children's well-being and motivation. The majority of these studies is descriptive, though, and - apart from Huber and Helm (2020) - did not examine multivariate interrelations between distant teaching activities and academic outcomes during the school lockdown.

\section{Effective teaching activities and students' motivational and learning success}




\section{SCHOOL LOCKDOWN DURING COVID-19 PANDEMIC}

Students' motivational development and achievement is strongly influenced by features of instruction and teaching (Brophy, 2004; Wentzel \& Miele, 2016). In their theoretical framework of generic dimensions of teaching quality, Klieme and colleagues (Klieme, Pauli, \& Reusser, 2009; Praetorius, Klieme, Herbert, \& Pinger, 2018) describe three basic dimensions of effective teaching: cognitive activation, classroom management, and learning support. These generic dimensions are substantially related to successful learning and thus need to be considered when implementing distant teaching during the school lockdown (Voss \& Wittwer, 2020). In this context, it might be possible that different distant teaching activities contribute differently to students' outcomes during the school lock down (Eickelmann \& Gerick, 2020). For example, an effective classroom management defined by actions of the teacher to establish order, or to elicit cooperation among students (Emmer \& Stough, 2001) might be of less importance. However, other activities such as cognitive activation in learning processes, clarity of instruction, comprehensibility and structure of tasks, effective support through regular feedback, and individualized learning support can theoretically be realized in distant teaching and are expected to be highly salient when aiming to enhance students' motivation, learning behaviours and achievement during the school lockdown.

Cognitive activation refers to the encouragement of students to develop their own solutions, to try out multiple solution paths and to critically evaluate their own solutions (Baumert et al., 2010), and also refers to the provision of challenging tasks that draw on students' prior knowledge (Hiebert \& Grouws, 2007). Cognitive activation is positively related to students' achievement (Fauth et al., 2019; Schiepe-Tiska, Heine, Lüdtke, Seidel, \& Prenzel, 2016). Relations between cognitive activation and students' motivation are somehow unresolved. Some studies found non-significant effects on students' motivation in elementary (Fauth et al., 2019) and secondary school (Schiepe-Tiska et al., 2016), whereas other studies found positive relations between cognitive activation and students' enjoyment in elementary 


\section{SCHOOL LOCKDOWN DURING COVID-19 PANDEMIC}

(Fauth, Decristan, Rieser, Klieme \& Büttner, 2014) and in secondary school (Lazarides \& Buchholz, 2019). In times of distant teaching, possible ways to implement cognitive activation is providing opportunities for students to get involved with the learning content on a higher-order level, for example, through tasks that challenge cognitive involvement (e.g., discussing multiple solution paths). Thus, students can be cognitively activated by cooperative learning activities in which they exchange thoughts and explanations (Voss \& Wittwer, 2020). In this context, research showed that, in elementary school, the majority of tasks during the school lockdown were repetitions and practice tasks (see also Sliwka \& Klopsch, 2020); and that in high school, tasks were overall neither diverse nor cognitively activating as indicated by over $60 \%$ of the parents (Wildemann \& Hosenfeld, 2020). Therefore, only sending out tasks and solutions as realized often during the school lockdown (Porsch \& Porsch, 2020) might not contribute to students' successful learning. In this study we expect that the encouragement to critically evaluate own solutions (Baumert et al., 2010) through regular task-related feedback by the teacher enhances learners' motivation, learning behaviors, and learning progress (e,g., Klieme, 2020).

Learning support is particularly important for students' motivational development (Huber \& Helm, 2020; Klieme, 2020; Klieme et al., 2009) and is characterized, for example, by emotional supportive teacher-student relationships, and adaptive and individualized learning support by the teacher (Praetorius et al., 2018). Teacher-student relationships have been shown to be highly relevant for students' intrinsic motivation to learn (Niemiec \& Ryan, 2009), academic effort, and valuing of learning (Goodenow, 1993; Roeser, Eccles \& Sameroff, 1998). Thus, we suggest that student-teacher communication is highly relevant for students' motivation, learning behaviors, and learning progress during the school lock down. Individualized learning support is also highly relevant for students' motivation (Huber \& Helm, 2020; Klieme, 2020; Van de Pol, Volman \& Beishuizen, 2010). Individual support in terms of task-related feedback has been outlined in research on effective instruction as one of 


\section{SCHOOL LOCKDOWN DURING COVID-19 PANDEMIC}

the strongest predictors of students' achievement (Hattie \& Timperley, 2007), but also on students' motivation (e.g. Weidinger, Spinath \& Steinmayr, 2016). Both, emotional and individualized support have - at least in some cases - been reduced during the school lockdown as compared to regular classroom settings (Huber \& Helm, 2020; Porsch \& Porsch, 2020; Wacker et al., 2020). According to the Landau study, $35.6 \%$ of parents indicated that their child's teacher did not asks for assignments to be sent back; $18.4 \%$ of the children never or seldom received feedback from teachers, $17.9 \%$ sometimes and only $26.1 \%$ received feedback regularly; similar results were obtained in other studies (Porsch \& Porsch, 2020; Wacker et al., 2020). However, these results have to be interpreted with caution as they refer to few empirical studies that mainly investigated families with a relatively high socioeconomic background. More research is needed that examines the quantity and quality of support and contact during the school lockdown. Given the importance of student-teacher communication, we assume that distant teaching activities that comprise interpersonal forms of communication positively relate to motivation, learning behaviors and learning progress whereas more indirect forms of support or feedback (e.g., grading or sending out tasks) are less important for these academic outcomes.

Supportive teaching is strongly interrelated and often even depends on the effective cooperation between teachers and parents (Ma, Shen, Krenn, Hu, \& Yuan, 2016). Students whose teachers succeed in building cooperative relationships to their parents are highly likely to be engaged in learning and experience higher achievement gains across time than their peers with lower teacher-parent relationship quality (Hughes \& Kwok, 2007). In the Landau study on distant teaching, the majority of parents $(62.7 \%)$ stated that they did not have any exchanges with teachers during the school lockdown, apart from emails teachers sent with weekly assignments (Wildemann \& Hosenfeld, 2020). This lack of communication was also shown by others (Köller, Fleckenstein, Guill, \& Meyer, 2020; Porsch \& Porsch, 2020). However, it needs to be taken into account that despite teachers' willingness to cooperate with 
their students, they often did not feel prepared for the situation of distant teaching (Runge et al., 2020), calling for a need for more professional training within the context of methods for distant teaching and teaching quality in the context of digital tools. Particularly students in elementary school need additional teacher support during times of school lockdowns because young students do not seek autonomy from adult socializers yet (Havighurst, 1948) whereas secondary school students are more autonomous and more independent (Eccles \& Roeser, 2009). Therefore, we hypothesize that perceived teacher support (e.g., provided by communicating with the teacher, and cooperation between parents and teachers) matters more in elementary school than in secondary school.

\section{Student and family characteristics}

Apart from teaching activities, student and family characteristics matter for students' individual achievement (see Köller, 2012) and motivation (e.g., Steinmayr, Dinger, \& Spinath, 2012; Weidinger et al., 2016). According to the expectancy-value theory (EVT; Eccles [Parsons] et al. 1983; Wigfield, Tonks, \& Klauda, 2016), students interpret current achievement situations against the background of their current abilities, their own temperament, and their perceptions of the beliefs and behaviour of relevant others, like their parents. Students' achievement motivation (i.e., their expectancies and values) depends on this (un)conscious interpretation and determines whether students will engage in tasks and will do well in school or not. Therefore, students' academic outcomes during the school lockdown should be substantially related to students' temperament (e.g., negative emotionality), school engagement, and competencies (Sliwka \& Klopsch, 2020). A variety of studies demonstrated substantial relations between these factors and students' academic outcomes (e.g., Hintsanen et al., 2017; Steinmayr, Weidinger, \& Wigfield, 2018; Šimunović \& Babarović, 2020) in elementary and secondary school. Moreover, studies frequently demonstrated the association between social background variables and academic achievement as well as learning motivation, in general and during the school lockdown (e.g., Steinmayr et 
al., 2012; Huber \& Helm, 2020). Overall $86 \%$ of teachers who participated in the German School Barometer (2020) stated that effects of social inequality would be intensified due to the school lockdown during the pandemic, with $31 \%$ (Grammar School) to $39 \%$ (basic schooling/“Hauptschule”) of teachers assuming significant achievement delays of their students.

\section{Aims of the present study}

Hitherto, there are few studies investigating how differences in distant teaching activities between teachers were related to important student outcomes during the school lockdown caused by the COVID-19 pandemic.

The first aim of the present study therefore was to investigate how distant teaching was realized in schools in Germany. Because different teaching activities influenced students' cognitive, motivational and affective learning outcomes in regular classroom settings (e.g., Baumert et al., 2010; Lazarides \& Buchholz, 2019), we expected that different forms of distant teaching (e.g., grading, sending tasks vs. task-related feedback, provision of solutions, direct communication with students and parents) would be differentially associated with students' motivation, learning behaviors and achievement during the school lockdown. We thereby also considered differential effects depending on the school level (elementary versus secondary school) under investigation. More precisely, we expected that teacher communication and feedback would be more important in younger age groups, and thus, for elementary school students' motivation, learning behaviors and achievement. Unlike other studies that asked how teachers realized distant teaching on a general level (e.g., Huber \& Helm, 2020), we asked how teachers in specific subjects acted during the school lockdown (see also Wildemann \& Hosenfeld, 2020) to exploratorily investigate whether there are subject-specific differences.

Furthermore, studies indicated that students' individual characteristics and familyrelated socio-economic resources were substantially associated with students' motivation, 


\section{SCHOOL LOCKDOWN DURING COVID-19 PANDEMIC}

their behavior, and achievement during the school lockdown (e.g., Huber \& Helm, 2020; Sliwka \& Klopsch, 2020; Porsch \& Porsch, 2020). Thus, the second aim of the present study was to investigate whether differences in distant teaching would be associated with students' motivation, learning behavior, and achievement during the school lockdown controlling for students' background variables and individual characteristics. In terms of learning behaviors, we focus on competent and independent learning during the school lockdown, which is important because it is strongly related to students' intrinsic motivation and is known to relate to students' overall academic attainment (Klieme, 2020; Wild, Rammer \& Siegmund, 2006).

To address these objectives, parents gave information on students' individual characteristics (i.e., negative emotionality, school engagement, and competencies in math and language arts), and on the child's social background, resources and their own educational level beside distant teaching activities. Furthermore, we assessed indicators of wealth goods (see Wendt, Bos, Goy \& Jusufi, 2017), which we considered to be important during the school lockdown, for example having an own bedroom or possessing a computer or tablet that she/he could use during the school lockdown (see also Huber \& Helm, 2020; Wacker et al., 2020). Moreover, we asked for child's and parent's gender and age as at least children's gender and age are important predictors of academic outcomes (see Herbert \& Stipek, 2005).

By this means we wanted to extend the findings by Huber and Helm (2020) by considering more student characteristics and socio-demographic variables as predictors of students' academic outcomes during school lockdown (Huber and Helm: students' autonomy and age, parental support, family situation during the pandemic, technical resources; present study: students' negative emotionality, school engagement, and competencies in math and language arts, students' as well as parents' age and gender, technical resources, an own room for the child, parents' education and migration background). Specifically, we aimed at investigating the following research questions: 


\section{SCHOOL LOCKDOWN DURING COVID-19 PANDEMIC}

RQ1: How are distant teaching activities associated with students' motivation, competent and independent learning, and learning progress during the school lockdown?

RQ2: Do different teaching activities play a different role for elementary vs. secondary school students' motivation, competent and independent learning, and learning progress during the school lockdown?

RQ3: Are those distant teaching activities that involve direct forms of interpersonal feedback and communication (e.g., task-related feedback, teaching via videoconference, and student-teacher communication) particularly strongly related to students' motivation, competent and independent learning, and learning progress during the school lockdown when simultaneously taking into account other forms of distant teaching activities (e.g., grading, frequency of sending out tasks)?

RQ4: Do students' characteristics and social background variables add to the variance explanation of students' motivation, competent and independent learning, and learning progress during the school lockdown above distant teaching activities?

\section{Method}

\section{Procedure}

The study was conducted online. Parents filled in the online questionnaire between April and July 2020, during the global "Corona crisis" (the COVID-19 pandemic). To reduce the risk of infection, most schools had been closed in Germany from March 2020 onwards for several weeks, generally until the national summer holidays. We recruited parents from all over Germany by posting the study link on Facebook.com and Twitter.com. Additionally, we contacted 28 parent associations from all federal states in Germany between April and May 2020 by email. Finally, we disseminated the study link by ourselves via our University homepages and via personal contacts and email distribution lists.

The completion of the online questionnaire took the parents about 20 minutes. If they had more than one child in school, parents were asked to decide for which child they filled in 


\section{SCHOOL LOCKDOWN DURING COVID-19 PANDEMIC}

the questionnaire. First, parents provided some demographic information about themselves and their child (e.g., gender, age, zip code, family status and size, language they spoke at home, gender, and age). In a second step, they were asked to answer several questions on distant teaching activities and student outcomes during the school lockdown. Finally, parents were asked to rate some characteristics of their child (e.g., school engagement, abilities in the domains of math and German).

The project is in accordance with established ethical guidelines for psychological research. The study was approved by the local review board at Philipps University Marburg. All participants provided written informed consent in accordance with the Declaration of Helsinki and its later amendments. Participation was voluntary. $N=3614$ clicked on the link to fill out the survey. However, 967 parents aborted the study and did not answer any questions.

\section{Participants}

A sample of 2,647 parents from Germany who had at least one child who had to learn at home during the school lockdown between March and July 2020 participated in this study. Parents from all German federal states except from Bremen took part in this study (for further information, see Supplement 1 in the Online Supplementary Material [OSM]).

The mean age of the parents was 43.37 years $(S D=5.66$ years). The majority of parents $(83.6 \%)$ was female $(15.9 \%$ male, $0.4 \%$ other $)$. Overall, $92.9 \%$ of the parents were born in Germany. Of the parents $77.4 \%$ had a university entrance certificate ("[Fach]Abitur"); $84.8 \%$ indicated to be the mother of the child for whom they filled in the questionnaire (father: $14.4 \%$, other child' s relative: $0.8 \%$ ). The sample was representative for the German population with respect to mean age (Federal Statistical Office, 2020b). However, females and parents with a university entrance certificate were overrepresented in the sample (Federal Statistical Office 2020a, 2020b), as it was also the case in other studies (e.g., Porsch \& Porsch, 2020; Wildemann \& Hosenfeld, 2020). 
The mean age of the children was $10.85(S D=2.70) ; 46.6 \%$ of the parents indicted that their child was "female" (male: $51.6 \%$; other: $1.6 \%$ ). About $40.2 \%$ of all children attended elementary schools, $37.5 \%$ academic track secondary schools (“Gymnasium”), $8.8 \%$ comprehensive secondary schools (“Gesamtschule”), $7.9 \%$ intermediate track secondary schools ("Realschule"), 0.8 \% lowest track secondary schools ("Hauptschule"), $0.6 \%$ schools for special educational needs ("Förderschule"), and $4.1 \%$ another school type. Children were in Grades 1 to 13 at the time the parents participated in this study. Fifth and sixth grade students living in Berlin or Brandenburg were labelled as elementary school students if their parents did not indicate that they attended the "Gymnasium". The latter is possible for gifted fifth and sixth graders in Berlin which applied for one student in this sample who we classified as secondary school student accordingly.

At the time their parents participated in this study, children had to learn at home because of the school lockdown for 9.18 weeks on average ( $S D=2.95$ weeks). We excluded parents of children who attended a school for special educational needs $(n=15)$ because these children have systematically different needs than students who are attending regular schools Furthermore, we excluded four participants due to unlikely answer patterns (e.g., all items were answered with a 1). The final analysis sample of this study thus comprised 2,628 participants.

\section{Instruments}

Motivation during the school lockdown. Two items assessed students' motivation during the school lockdown. The first one was "My child works motivated on the assignments during the school lockdown" and the second one "My child enjoys working on her/his assignments during the school lockdown." Both items were used in prior studies to assess motivation in school (self-ratings:Authors, 2010; parent-ratings: Authors, 2017) and are based on items used by Eccles and her colleagues (Eccles et al., 1983; Eccles \& Wigfield, 1995). In this study, we added "during school lockdown" to all items. Parents were asked to read 


\section{SCHOOL LOCKDOWN DURING COVID-19 PANDEMIC}

through the items and indicate whether the following statements apply to their situation at home during the school lockdown. They answered the items on a 5-point Likert scale with the following answer options: 1 "Strongly disagree", 2 "Disagree", 3 "Neutral”, 4 "Agree" and 5 "Strongly agree". The two items were combined to a "motivation during the school lockdown" scale, which had a high reliability (see Table 2).

Competent and independent learning during the school lockdown. Three items assessed whether the children were able to work competent and independently on school tasks during the school lockdown, that is, without parental support. The items were the following: "My child accomplishes her/his assignment during the school lockdown without any difficulties", "My child only accomplishes her/his assignment during the school lockdown with my or my partner's help" (reversely coded), and "My child needs a lot of support for doing her/his school tasks during the school lockdown" (reversely coded). The first item was used in prior studies to assess self-perceived competencies in school (e.g., Authors, 2009; Schöne, Dickhäuser, Spinath \& Stiensmeier-Pelster. 2002). It was reformulated for parentratings and it referred to the school lockdown situation. The two other items were developed for the present study referring to Wild et al. (2006; see also Jopt, 1978). Parents answered the items on the same scale as the motivation items. The scale's reliability was high (see Table 2), indicating that the items assessed competent and independent learning as described in Wild et al. (2006).

Learning progress during the school lockdown. The item "My child learns a lot during the school lockdown" assessed parents' perception of their child's learning progress during the school lockdown. The item was part of the parent questionnaire in TIMSS 2015 (Wendt et al., 2017) assessing how content parents are with their children's school. We chose this item because it was the only one referring to learning progress. We added "during the school lockdown". Parents answered the item on the same scale as the motivation items. The 


\section{SCHOOL LOCKDOWN DURING COVID-19 PANDEMIC}

item correlated in the expected direction with the other items; for example, correlation with "motivation during the school lockdown" was high (see Table 2).

Distant teaching activities. Items assessing how schools realized distant teaching during the school lockdown were developed for this project. The different German federal states only gave recommendations on how to realize distant teaching and did not provide promulgations. Based on these recommendations and further teaching aspects influencing students' motivation and learning that might theoretically be realized in distant teaching, we created eight items assessing the perceived frequency at which the main subject teachers (mathematics, language arts, English) and the science/biology teachers realized these aspects. Specifically, we asked the parents for the frequency at which the teacher sent tasks and solutions, requested students' solutions, gave feedback on those, graded students' solutions, taught via videoconference, and had contact with the child and/or parent via chat, e-mail or phone. Answers were given on a scale with six answer options: 1 "Not yet", 2 "Every three weeks", 3 "Every two weeks", 4 "Every week", 5 “Twice per week”, 6 “Three times per week or more". Parents were asked to answer these questions for every subject even if the same teacher taught these subjects. Items referring to the same distant teaching activity were summed up indicating how this aspect of distant teaching was realized in general at the school that the rated child attended. Reliabilities were at least satisfactory (see Table 2).

Parent ratings of student characteristics. Parents were instructed to compare their child with children of the same age when rating their child's negative emotionality, school engagement, and math and language arts abilities. Parents answered all items on a 7-point scale. For each of the seven points of the scale, we indicated the percentage of students from the overall population that would be in this category, given a normal distribution: 1 = "far below average [about $2 \%$ of all students]", 2 = "below average [about $14 \%$ of all students]", 3 $=$ "slightly below average [about $15.5 \%$ of all students]", 4 = "average [about $37 \%$ of all students]", 5 = "slightly above average [about $15.5 \%$ of all students]", $6=$ "above average 


\section{SCHOOL LOCKDOWN DURING COVID-19 PANDEMIC}

[about $14 \%$ of all students]", $7=$ "far above average [about $2 \%$ of all students)". All items had previously been used in a parent survey (Authors, 2017; Authors, 2019).

Negative emotionality. In this study, negative emotionality refers to the child's tendency to easily experience negative feelings such as anger. Parents' perception of their child's negative emotionality was assessed with the following four items that were adapted from the Personality questionnaire for children between the age of 9 and 14 (Persönlichkeitsfragebogen für Kinder zwischen 9 und 14 Jahren, PFK 9-14; Seitz \& Rausche, 2019): "My child is easily annoyed about something", "It is mostly difficult for my child to be patient", and "My child gets angry quickly". We excluded the item "My child is often afraid of a class test." In preliminary analysis with this sample and the sample depicted in Authors (2019), we conducted exploratory factor analysis. The test anxiety item did not load highly on the negative emotionality factor $(\lambda s<.5)$ and had a high cross-loading $(\lambda s>$ .3). Reliability of the scale with three items was high.

School engagement. Parents' perception of their child's school engagement was assessed with the short version of the Behavioral Engagement and Disaffection scales developed by Skinner, Kindermann, and Furrer (2008). We assessed behavioral engagement with the following items: "My child tries hard to do well in school", "My child listens carefully if someone explains something to her/him", and "My child always takes an effort to do her/his homework well."

Math and language arts abilities. Parents' perception of their child's abilities in the domain of math was assessed by the following three items (adapted from Lorenz, 2011): "My child is talented in math", "My child has a good understanding of mathematical relations", and "My child can solve arithmetic problems well." Parents' perception of their child's ability in the domain of language arts was assessed by the following four items (adapted from Lorenz, 2011): "My child is talented in German", "My child can understand texts well”, "My child has an extensive vocabulary", and "My child can read well." 
Social background. Four items assessed families' social background. First, we asked for the rater's highest school leaving certificate ("No school leaving certificate", "lower vocational track leaving certificate [Hauptschulabschluss]", "higher vocational track leaving certificate [Mittlere Reife]", "lower academic track school leaving certificate [Fachhochschulreife]", "higher academic track school leaving certificate [Allgemeine Hochschulreife]", and "others"). The variable was dummy-coded by recoding no or vocational track leaving certificates as 0 and both academic track school leaving certificates as 1. "Others" were coded as missing (-99). Second, parents indicated if they were born in Germany or in a different country as a measure of migration background. The variable was also dummy-coded with 0 "born in Germany" and 1 "not born in Germany". Third, we assessed whether the rated child had a bedroom for her-/himself, and whether the child had a computer or tablet at her/his disposal for her/his assignments during the school lockdown (see Wendt at al., 2017). Answer options for the latter two items were 0 "no" and 1 "yes".

Further demographics. Additionally, we considered children's and parents' age and gender. Children's and parents' gender was dummy-coded with 0 "male" and 1 "female".

\section{Statistical Analyses}

Descriptive statistics were calculated with SPSS 26. We applied MPlus Version 7.4 (Muthén \& Muthén, 1998-2015) to examine the measurement models of distant teaching activities and to set up structure equation models (SEMs) investigating simultaneously distant teaching activities and students' outcomes during the school lockdown with and without students' characteristics. We used weighted least square mean and variance adjusted (WLSMV) as a parameter estimator because most items were only ordinal and nearly all outcomes were skewed and not normally distributed. Data depended on the educational system of the different federal states. Furthermore, due to the different data gathering methods (see above) it could not be excluded that data in all federal states were selected with the same probability. This might result in distorted standard errors (see McNeish, Stapleton \& 


\section{SCHOOL LOCKDOWN DURING COVID-19 PANDEMIC}

Silverman, 2017; Stapleton, McNeish \& Yang, 2016). Thus, we used type = complex to control for the nested data structure (see Asparouhov, 2005, 2006).

Figure 1 depicts, among others, the measurement model of distant teaching activities (for more information on the measurement model of distant teaching activities see Supplement 2 in the OSM). The SEMs were set up in the following way: In the first model, the eight distant teaching activities were simultaneously regressed on parent rated student's motivation, competent and independent learning, and learning progress during distant learning (see Figure 1). ${ }^{1}$ Perceived motivation and competent and independent learning were modelled as latent factors, learning progress as manifest variable. Residuals of the endogenous factors and learning progress were correlated. Furthermore, all exogenous factors correlated as set as default in MPlus. Then, parent rated child's general negative emotionality, school engagement, abilities in math and language arts (all modelled as latent factors), dummy-coded parent's highest school leaving certificate, migration background, possession of a laptop or a tablet during school lockdown, possession of an own bedroom, child's and parent's gender and age were additionally regressed on parent rated student's motivation, competent and independent learning, and learning progress. All exogenous variables were correlated to

\footnotetext{
${ }^{1}$ The teacher factors were not considered as predictors in the following analyses. It might be that teachers differed in the frequency at which they realized different distant teaching activities depending on the subject they taught, but there is no theoretical rationale to assume that the subject-specific teacher factors would add to the prediction of students' motivation, competent and independent learning, and learning progress during the school lockdown after controlling for the realized distant teaching activities. Furthermore, we did not assess students' motivation, competent and independent learning, and learning progress during the school lockdown domainspecifically. In line with these thoughts, regression models demonstrated that the teacher variables did not add to the prediction of these dependent variables.
} 


\section{SCHOOL LOCKDOWN DURING COVID-19 PANDEMIC}

ensure that the path weights on the three endogenous variables can be interpreted as a unique effect of the exogenous variables. ${ }^{2}$

Analyses were run for the total sample and separately for elementary and secondary schools as we assumed some distant teaching activities to be differently important for elementary and secondary school students (RQ 2). ${ }^{3}$

\section{Results}

\section{Descriptive Statistics}

Since the school lockdown was completely new for everyone, we will first present the frequencies concerning the distant teaching quality items to gain an overview on how distant teaching was realized at different schools. Table 1 shows the frequencies for the total sample (separate tables and figures for elementary and secondary school can be found in Supplements 3-5 in the OSM).

\section{[Insert Table 1 about here]}

Most teachers realized distant teaching by sending tasks to the students. Between $45 \%$ (science/biology) and $67 \%$ (math) teachers also sent solutions for these tasks. Requesting students' solutions of the sent tasks applied to $51 \%$ (science/biology) to $68 \%$ (language art) of the teachers. However, only $33 \%$ (science/biology) to $50 \%$ (language art) of all teachers gave feedback on students' solutions. Only $5 \%$ (science/biology) to $8 \%$ (language art) of all teachers graded students' solutions. The percentage of teachers' teaching via video conference

\footnotetext{
${ }^{2}$ We included all predictors simultaneously in the model. However, if a reader is interested in model results when including students' characteristics and demographics stepwise, please contact the first author.

${ }^{3}$ We checked whether secondary schools differed in the models described below. Only the elementary school sample and the "Gymnasium" sample were large enough for SEM. Thus, we performed regression analyses with manifest variables for all secondary school types to check for potential differences between them. On a descriptive level, path weights did not greatly differ between secondary school types. Thus, we decided to perform all analyses for the combined secondary school sample.
} 


\section{SCHOOL LOCKDOWN DURING COVID-19 PANDEMIC}

was also small (9\% in science/biology to $23 \%$ in language art). Between $28 \%$ (science/biology) to $46 \%$ (language art) of all teachers had contact with their students via telecommunication tools. About $20 \%$ (English) to $34 \%$ (language art) of the teachers had contact with a parent via telecommunication tools. Furthermore, how often teachers realized the different distant teaching activities varied greatly between them. If a teacher realized a distant teaching activity, it was mostly realized once a week.

School level differences were shown between elementary and secondary school English and science/biology teachers. In elementary school, the focus was clearly on distant teaching of math and language arts. The frequencies at which distant teaching activities were realized in English and science were all lower than the same activities realized for math and language arts. Furthermore, there were also some (smaller) differences between elementary and secondary school depending on the focused activity in the same subject (e.g., contact with a parent).

Table 2 shows descriptive statistics and bivariate correlation for the overall sample (separate tables for elementary and secondary school can be found in Supplements 6 and 7 in the OSM). For the distant teaching activities, we conducted non-parametric correlations.

\section{[Insert Table 2 about here]}

As assumed in our first research question (RQ 1), most distant teaching activities correlated positively with students' motivation, competent and independent learning, and learning progress during the school lockdown. The same was true for the elementary school subsample. However, effect sizes were rather small (see Table 2). Giving feedback and communicating with the child demonstrated the highest correlations with students' motivation, competent and independent learning, and learning progress during the school lockdown for both elementary and secondary school. All student characteristics (negative emotionality, school engagement, math and language art competencies) correlated lower than $r=.10$ with distant teaching activities with one exception: the higher parents rated their 


\section{SCHOOL LOCKDOWN DURING COVID-19 PANDEMIC}

child's negative emotionality, the more often they had contact with the teacher. Distant teaching activities were not significantly correlated with sociodemographic variables or the association was minuscule with one exception: child's age. Child's age mostly displayed medium correlations with distant teaching activities. Thus, the older the children, the more often teachers realized distant teaching activities.

In line with RQ 2, some associations between distant teaching activities and students' motivation, competent and independent learning, and learning progress differed between elementary and secondary schools: sending solution $\mathrm{x}$ learning progress: $z=-2.278, p=.022$; requesting students' solution $\mathrm{x}$ motivation: $z=-2.002, p=.046$; requesting students' solution $\mathrm{x}$ competent and independent learning: $z=-2.128, p=.034$; requesting students' solution $\mathrm{x}$ learning progress: $z=-2.735, p=.006$; feedback x motivation: $z=-3.586, p<.001$; feedback $\mathrm{x}$ competent and independent learning: $z=-2.52, p=.012$; feedback x learning progress: $z=-$ 3.592, $p<.001$; student-teacher communication $\mathrm{x}$ learning progress: $z=-2.956, p=.004$; parent-teacher communication x motivation: $z=2.636, p=.008$; parent-teacher communication $\mathrm{x}$ competent and independent learning: $z=2.841, p=.004$. Correlations were higher in the secondary school sample besides the correlations concerning "parent-teacher communication"; in that case they were higher in the elementary school sample. Given the partly different correlations, SEMs were performed for the total sample and separately for the elementary and secondary samples.

\section{Structural Equation Models}

First, we tested the measurement model of the distant teaching activities (measurement model depicted in Figure 1). The model demonstrated an excellent model fit: $\chi^{2}(d f=366)=$ $490.18, p<.001 ; \mathrm{RMSEA}=.012(90 \%$ confidence interval: $.009 ; .014) ; \mathrm{CFI}=.997 ; \mathrm{TLI}=$ .996.

Second, we regressed the different teaching activities and students' characteristics on students' motivation, competent and independent learning, and learning progress during the 


\section{SCHOOL LOCKDOWN DURING COVID-19 PANDEMIC}

school lockdown (see Figure 1; results without students' characteristics and demographics can be found in Supplements 8 and 9 in the OSM). Table 3 displays correlations between residuals and model fit indices for the total sample, elementary and secondary schools. The model fit was excellent in all models. Table 4 depicts path coefficients from all independent variables to students' motivation, competent and independent learning, and learning progress for the different samples.

\section{[Insert Tables 3 and 4 about here]}

Student-teacher and parent-teacher communication significantly related to children's motivation; student-teacher communication significantly related to children's competent and independent learning; and teaching via videoconference and parent-teacher communication significantly related to children's learning progress during the school lockdown. In the secondary school sample, six out of eight distant teaching activities incrementally explained variance in students' motivation (sending solutions and teaching via video conference did not, grading had a negative path weight). Feedback, grading (negatively), and student-teacher communication incrementally explained variance in secondary school students' competent and independent learning, and learning progress during the school lockdown. Teaching via video conference incrementally contributed to students' competent and independent learning and parent-teacher communication to students' learning progress during the school lockdown. Thus, in line with RQ3 those distant teaching activities that involve direct forms of interpersonal feedback and communication particularly contributed to the variance explanation of students' academic outcomes during school lockdown. However, in line with RQ4 children's characteristics, especially negative emotionality (negative association) and school engagement (positive association), incrementally contributed to students' academic outcomes during school lockdown. In both samples, students' math and language art competencies incrementally explained variance in students' competent and independent learning during the school lockdown. In secondary school, math and language art 


\section{SCHOOL LOCKDOWN DURING COVID-19 PANDEMIC}

competencies negatively related to motivation and learning progress during the school lockdown. Among the socio-economic variables, parents' highest school leaving certificate significantly explained variance in secondary school students' motivation and competent and independent learning, and in elementary students' competent and independent learning, and their learning progress. Students' age had a positive path weight on secondary school students' motivation and competent and independent learning, but a negative path weight on elementary school students' learning progress.

\section{Discussion}

Teachers in this study greatly varied in how they realized distant teaching. Distant teaching activities were associated with parents' perceptions of students' academic outcomes during the school lockdown, replicating the overall results of the Landau Homeschooling Study and the School Barometer (Huber \& Helm, 2020; Wildemann \& Hosenfeld, 2020). After additionally controlling for parents' perceptions of students' characteristics (negative emotionality, school engagement, math and language art competencies), socio-economic and demographic variables, teachers' distant teaching activities were still associated with students' outcomes during the school lockdown (see also Huber \& Helm, 2020). Students' characteristics explained most variance in students' outcomes during the school lockdown, as did positive emotionality and independence in the study by Huber and Helm (2020). Students' socio-economic background variables were also associated with students' outcomes during the school lockdown (see Porsch \& Porsch, 2020).

\section{Realization of distant teaching activities}

The majority of teachers realized distant teaching activities by sending out tasks and solutions once a week, similar to recent results obtained by others (Deutsches Schulbarometer, 2020; Porsch \& Porsch, 2020; Wildemann \& Hosenfeld, 2020). Whereas $41.8 \%$ of the children in the Landau study always or almost always received feedback on their assignments (Wildemann \& Hosenfeld, 2020), only between 16 (biology/science) to 


\section{SCHOOL LOCKDOWN DURING COVID-19 PANDEMIC}

$25 \%$ (math and language art) of the children in our study got teacher feedback. In both studies, student's assignments were predominantly (> 50\%) not requested to be sent back, and - in our study - in over $90 \%$ not graded by teachers. As giving feedback on an assignment requires sending it to the teachers, it might well be that feedback in the present study and in the Landau study was differently operationalized. Comparable to the Landau study, teachers of elementary school children focused on math and language art assignments, whereas students in secondary school received more tasks of diverse subjects. However, the differences between subjects should be interpreted with caution given that different frequencies might be expected to replicate the standard time tables. The main subjects (math, language arts, and, in secondary school, English) are taught with more hours than other subjects, and the results by Porsch and Prosch (2020) also demonstrate a focus on math, language art and biology/science assignments.

The majority of teachers in our study was not in direct contact with either children or parents and did not use any form of video conferences across subjects $(76.6 \%$ to $90.8 \%$; see Table 1). This is in line with the German School Barometer (2020) and the study by Thorell et al. (under review) with only $24 \%$ children in Sweden receiving video conferences. Thus, even in countries more advanced in digital teaching such as Sweden, the vast majority of children completed tasks and materials during the school lockdown by themselves and/or the support of their parents (see also Porsch \& Porsch, 2020; Wacker et al., 2020). As in other studies, the supporting parent were mothers in over $80 \%$ of cases with on average high educational backgrounds (Thorell et al., under review; Porsch, \& Porsch, 2020; Wildemann \& Hosenfeld, 2020). Furthermore, the majority of children had a room of their own as well as a computer or tablet that they could use for their assignments during the school lockdown. This conforms to previous studies indicating that the majority of participants in online studies are better educated and equipped than the basic population (Porsch \& Porsch, 2020; Wildemann \& 
Hosenfeld, 2020; Thorell et al., under review). Thus, the majority of investigated students had the prerequisites for being taught via video conferences, etc.

The reasons for the rare realization of direct contact between teachers and students during the school lockdown need to be investigated in further studies. First studies that also included the perspective of the teachers identified the need for better preparation for distant teaching (Runge et al., 2020), which should be initiated and organized by school principals and educational institutions concerned with teacher training. Other related possible reasons are the lack of technical equipment provided by the schools, data security issues and no clear direction from the federal educational ministries (Eickelmann \& Gerick, 2020; Sliwka \& Klopsch, 2020).

\section{Differences between elementary and secondary schools}

Regarding school level differences between elementary and secondary schools (RQ 2), we found that distant teaching activities differed in their association with students' academic outcomes during the school lockdown. In most cases, correlations were higher in secondary school than in elementary school. Consequently, distant teaching explained a lower proportion of variance in students' academic outcomes in the elementary school sample compared to the secondary school sample in this study, replicating the results of the Landau Homeschooling Study (Wildemann \& Hosenfeld, 2020). Most distant teaching activities were more frequent in secondary school than in elementary school. Thus, the higher variance in distant teaching activities in secondary school raised the chance to identify predictive effects in this subsample. Further studies could investigate the role of developmental effects in this context.

\section{Distant teaching activities and students' academic outcomes}

Distant teaching activities that corresponded with dimensions of teaching quality (Baumert et al., 2010; Klieme et al., 2009), namely giving task-related feedback (i.e., cognitive activation) and communicating with the child (i.e., learning support), demonstrated the highest correlations with students' motivation, competent and independent learning, and 


\section{SCHOOL LOCKDOWN DURING COVID-19 PANDEMIC}

learning progress during the school lock down for both elementary and secondary school students (RQ 1). This is in line with the results obtained by Huber and Helm (2020). However, as the majority of teachers did not practice certain distant teaching activities, such as giving feedback, the variance of those items was restricted which might have led to diminished correlations with students' variables during school lockdown and to results diverging from other studies (feedback: Huber \& Helm, 2020).

The provision of tasks and task solutions was related to students' motivation to learn (only secondary schools), but not to their competent and independent learning or learning progress. However, we did not assess the cognitively activating potential of the provided tasks. The Landau Homeschooling Study demonstrated that the majority of teachers focused on the repetition of previously learned content, often in combination with some new things, though tasks and assignments were predominantly not creative or diverse (Wildemann \& Hosenfeld, 2020). Taken together, our results indicate that only assigning tasks is not enough to enhance students' cognitive learning processes (see Klieme, 2020).

Our finding emphasize a need for learning support as it was the factor communicating with the child that demonstrated the highest correlations with students' learning outcomes during the school lockdown for both elementary and secondary school students. A lack of communication between teachers and students that was also reported in previous research for the time of distant teaching during the school lockdown (Huber \& Helm, 2020; Porsch \& Porsch, 2020; Wacker et al., 2020) is therefore highly concerning.

In line with these thoughts is the presented importance of teacher's feedback to students in secondary school for students' academic outcomes. In elementary school, the association was also positive but did not hold after controlling for further variables. Our findings emphasize that task-related direct feedback seems to be a central factor of effective distant teaching for adolescent learners (Klieme, 2020). 


\section{SCHOOL LOCKDOWN DURING COVID-19 PANDEMIC}

Regarding direct communication, our findings showed that communication between students and teachers was relevant for students' motivation and competent and independent learning across samples. This finding is in line with theoretical assumptions that supportive teacher-student relationships are a central factor in enhancing motivational development (Klieme et al., 2009). Moreover, this finding extends such assumptions by showing that direct communication is particularly important during times of school lockdowns for all age groups (Klieme, 2020; Köller et al., 2020; Sliwka \& Klopsch, 2020). Thus, although we expected that direct communication between students and teachers would be particularly important for students in elementary school, our findings emphasize its importance for both elementary and secondary school students. This also pertains to parental support and parent-teacher cooperation, which are often seen as particularly important for younger students (Eccles \& Roeser, 2009). Parents' self-efficacy as well as support from school were the most significant predictors for parental strain, anxiety and teaching enthusiasm in the study by Porsch and Porsch (2020). In line with this, our findings emphasize that an effective parent-teacher communication enhanced parent-reported students' motivation and learning progress across age groups. This finding is of high relevance, as less than $50 \%$ of teachers were in regular communication contact with children and parents in our study. This finding corroborates theoretical considerations about teaching quality in times of distant teaching that also highlight the importance of regular and caring interaction between teachers and students through digital technologies (Voss \& Wittwer, 2020).

\section{The role of students' characteristics and socio-demographic background}

\section{variables}

Comparable to explaining differences in students' achievement and motivation in school teaching (e.g., Köller, 2012;), students' characteristic explained most variance in students' outcomes during the school lockdown among all relevant variables. Among students' characteristics, negative emotionality and school engagement explained most 


\section{SCHOOL LOCKDOWN DURING COVID-19 PANDEMIC}

variance whereas math and language art competencies were less relevant. Negative emotionality limits attention and leads to more conflicts with parents (see Hernández et al., 2016). Our results are in line with recent studies showing that especially parents of children suffering from ADHS reported the most difficulties and stress during the school lockdown (Thorell et al., under revision), and that negative emotionality was significantly associated with increased learning time (Huber \& Helm, 2020).

The important role of students' engagement is completely in line with previous studies that demonstrated positive relations between students' engagement, motivation, and achievement (e.g., Steinmayr et al., 2018). Engagement in tasks might have led to better learning and higher achievement during the school lockdown, which in turn might have strengthened students' motivation for learning during the school lockdown (see also Bandura, 1986).

Parent-rated math and language arts competencies correlated positively with all distant learning outcome variables. However, when considered in the full model, we partly found an unexpected negative relationship. As we can exclude multicollinearity as an explanation based on the maximum medium correlations between variables, this unexpected effect might be explained by a spurious suppression effect. Because suppression effects should only be interpreted on the basis of a strong theoretical rational (Watson, Clark, Chmielewski, Koty, 2013) and we are not aware of any theory explaining this effect, we do not further interpret it.

Parent-reported socio-demographic background contributed to the prediction of students' students' academic outcomes during the school lockdown (see also Fickermann \& Edelstein, 2020). Parents with an academic school-leaving certificate reported more positive student outcomes, which is in line with various studies on the link between socio-economic status, students' academic achievement and motivation (Sirin, 2005). Thus, not only in regular face-to-face schooling students academically benefit from their parents' academic education, but also during the school lockdown (see Porsch \& Porsch, 2020). Migration background did 


\section{SCHOOL LOCKDOWN DURING COVID-19 PANDEMIC}

not correlate with students' academic outcomes during school lockdown. The possession of an own computer did not incrementally contribute to the prediction of students' outcomes. As most teachers just sent tasks (Deutsches Schulbarometer, 2020), computers were in most cases only necessary to download assignments and thus were of minor importance for learning during the school lockdown. However, having an own bedroom contributed to the prediction of competent and independent learning in both samples. These results underline that especially children from low-income families were at risk during school lockdwon (see Fickermann \& Edelstein, 2020).

Children's age was still associated with students' academic outcomes during school lockdown after controlling for all other variables. The coefficients differed for elementary and secondary school. In elementary school, the younger children got better along during the school lockdown, whereas in secondary school the older students got better along. Up to the age of about ten, impulsivity increases and then decreases (Steinberg et al., 2008). As impulsivity is related to academic achievement (Vigil-Colet \& Morales-Vives, 2005), it might partly explain the diverging results in elementary and secondary school. Furthermore, older students are more autonomous and independent learners (Eccles \& Roeser, 2009), which might further explain the positive relationship between age and student outcomes during the school lockdown in secondary school.

\section{Limitations}

The study suffered from several limitations. First, we only assessed parents' ratings. The additional assessment of students' objective learning progress and self-rated students' motivation would have been desirable. During the school lockdown, it was hard to collect data from parents and their children, though. Therefore, researchers either relied on students' self-reports (see Huber \& Helm, 2020) or, as in the present study, on parent ratings (see also Wildemann \& Hosenfeld, 2020). We are not aware of any study that applied objective achievement tests during school lockdown or assessed data with more than one method. Like 


\section{SCHOOL LOCKDOWN DURING COVID-19 PANDEMIC}

all assessment methods, parental ratings come along with some disadvantages. Even though, moderator effects on parental ratings are not well investigated, older studies showed that parent-ratings are systematically biased by parents' stress level and their socio-economic status (SES), which is strongly associated with parental expectations and parents' psychopathy (Berg-Nielsen, Solheim, Belsky \& Wichstrom, 2012; De Los Reyes \& Kazdin, 2005). Given the stress level, parents reported during the school lockdown (Porsch \& Porsch, 2020; Thorell et al., under review) and given the parents' high educational level as an important indicator of socio-economic status, parents' answers were most likely slightly distorted in this and previous studies. However, prior studies demonstrated parent-ratings' validity for motivation (Wirthwein, Bergold, Preckel \& Steinmayr, 2019) and objectively measured competencies (Steinmayr, Weidinger, Heyder \& Bergold, 2019) and are thus valid proxies of students' actual motivation and competencies. In this study, parental ratings also correlated with other variables in the expected direction and magnitude, which underlines their validity (see also Herbert \& Stipek, 2005; Authors, 2019). Nevertheless, future studies should provide further evidence for the validity of the scales that have been used the for the first time in this study (e.g., by demonstrating their associations with students' self-ratings). Taken together, results should be interpreted with some caution but can overall be considered as valid.

Second, we used a cross-sectional design. Thus, the direction of the presented relations is unclear. However, as previous studies longitudinally demonstrated an impact of teaching activities on students' motivation and achievement (e.g., Lazarides \& Buchholz, 2019; Maulana, Opdenakker, \& Bosker, 2016), it might well be that teachers' distant teaching activities impacted on students' academic outcomes during the school lockdown. Third, students attending special educational need schools were excluded from the study as their number was too small and distant teaching activities for this group probably differ from distant teaching activities for students without special educational needs which is also true for 


\section{SCHOOL LOCKDOWN DURING COVID-19 PANDEMIC}

their parents' stress level (Goldan et al., 2020; Thorell et al., under review). Fourth, we only concentrated on four subjects. Considering more subjects would have led to a more comprehensive assessment of school's distant teaching activities. Last but not least, we did not focus on the determinants of distant teaching and on characteristics of the processes underlying distant teaching activities (e.g., obstacles and challenges that teachers faced when realizing distant teaching in Germany). These are important research questions for future studies in the field of distant teaching.

\section{Practical Implications}

All federal states in Germany returned to regular face-to-face schooling after the summer holidays 2020. However, as COVID-19 infection rates have been rising again, the risk of a new school lockdown is high. With respect to our results, the different educational ministries and schools should preventively prepare concepts of how to effectively implement distant teaching activities that keep up students' motivation, competent and independent learning, and learning progress, and should appropriately support teachers in realizing these teaching activities (see also Fickermann \& Edelstein, 2020). Therefore, schools should implement safe and stable systems that are accessible without barriers for teachers, students, and parents to keep up communication. Here, reaching out to socially disadvantaged children is important (Wrase, 2020; Köller et al., 2020). Prior studies showed that if about a third of a school year is lost (e.g., due to school closures or short school years), this is associated with about 3-4 \% less average income on the long-run (Wößmann, 2020). Increased child poverty and reduced educational opportunities are already a consequence of the current COVID-19 pandemic in Germany (Butterwegge, 2020; Fickermann \& Edelstein, 2020) and with respect to article 26 of the Universal Declaration of Human Rights, "everyone has the right to education. (...) Technical and professional education shall be made generally available and higher education shall be equally accessible to all on the basis of merit." (United for Human Rights, 2020). Furthermore, distant teaching activities mattered beyond students' 


\section{SCHOOL LOCKDOWN DURING COVID-19 PANDEMIC}

characteristics and socio-economic status. Thus, with regard to distant teaching and teaching in the classroom alike, our results highlight once again that teaching quality matters for students' outcomes (see Hattie, 2009). 


\section{References}

Authors, 2009

Authors, 2010

Authors, 2017

Authors, 2019

Asparouhov, T. (2005). Sampling weights in latent variable modeling. Structural Equation Modeling, 12, 411-434. doi 10.1207/s15328007sem1203_4

Asparouhov, T. (2006). General multi-level modeling with sampling weights.

Communications in Statistics: Theory and Methods, 35, 439-460. doi:

$10.1080 / 03610920500476598$

Bandura, A. (1986). Social foundations of thought and action: A social cognitive theory. Englewood Cliffs, NJ: Prentice-Hall.

Baumert, J., Kunter, M., Blum, W., Brunner, M., Voss, T., Jordan, A., . . Tsai, Y.-M. (2010). Teachers' mathematical knowledge, cognitive activation in the classroom, and student progress. American Educational Research Journal, 47, 133-180. doi: $10.3102 / 0002831209345157$

Berg-Nielsen, T. S., Solheim, E., Belsky, J. \& Wichstrom, L. (2012). Preschoolers' psychosocial problems: In the eyes of the beholder? Adding teacher characteristics as determinants of discrepant parent-teacher reports. Child Psychiatry and Human Development, 43, 393-413. doi: 10.1007/s10578-011-0271-0

Brophy, J. E. (2004). Motivating students to learn (2nd ed.). Mahwah, NJ: Erlbaum.

Butterwegge, C. (2020). Armut und materielle Ungleichheit im Zeichen der Corona-Krise. In U. Kemmesies und G. Trabert (Hrsg.), Solidarität in Zeiten von Corona und darüber hinaus. Ein Plädoyer für nachhaltige Armutsbekämpfung (S. 45-58). München: Oekom Verlag. 
De Los Reyes, A. \& Kazdin, A. E. (2005). Informant discrepancies in the assessment of childhood psychopathology: A critical review, theoretical framework, and recommendations for further study. Psychological Bulletin, 131, 483-509. doi: 10.1037/0033-2909.131.4.483

Eccles (Parsons), J. S., Adler, T. F., Futterman, R., Goff, S. B., Kaczala, C. M., Meece, J. L. et al. (1983). Expectancies, values, and academic behaviors. In J. T. Spence (Ed.), Achievement and achievement motives (pp. 75-146). San Francisco: Freeman.

Eccles, J. S. \& Roeser, R. W. (2009). Schools, academic motivation, and stage-environment fit. In R. Lerner \& L. Steinberg (Eds.), Handbook of adolescent psychology (pp. 404-434). New York: Wiley.

Eccles, J. S. \& Wigfield, A. (1995). In the mind of the actor: The structure of adolescents' achievement task values and expectancy-related beliefs. Personality and Social Psychology Bulletin, 21, 215-225. doi: 10.1177/0146167295213003

Eickelmann, B. \& Gerick, J. (2020). Lernen mit digitalen Medien. Zielsetzungen in Zeiten von Corona und unter besonderer Berücksichtigung von sozialen Ungleichheiten. In D. Fickermann \& B. Edelstein (Hrsg.), „Langsam vermisse ich die Schule ...". Schule während und nach der Corona-Pandemie (S. 153-162). Münster; New York: Waxmann. doi: $10.31244 / 9783830992318.09$

Emmer, E. T. \& Stough, L. M. (2001). Classroom management: A critical part of educational psychology, with implications for teacher education. Educational Psychologist, 36, 103112. doi: 10.1207/S15326985EP3602_5

Fauth, B., Decristan, J., Decker, A.-T., Büttner, G., Hardy, I., Klieme, E. \& Kunter, M. (2019). The effects of teacher competence on student outcomes in elementary science education: The mediating role of teaching quality. Teaching and Teacher Education, advanced online publication. doi 10.1016/j.tate.2019.102882 
Fauth, B., Decristan, J., Rieser, S., Klieme, E. \& Büttner, G. (2014). Student ratings of teaching quality in primary school: Dimensions and prediction of student outcomes. Learning and Instruction, 29, 1-9. doi: 10.1016/j.learninstruc.2013.07.001

Federal Statistical Office (2020a). Bevölkerung mit Migrationshintergrund-Ergebnisse des Mikrozensus 2019 [Population with migration background - Results of micro census 2019]. Wiesbaden, Germany: Author.

Federal Statistical Office (2020b). Pressemitteilung Nr. 223 vom 19.06.2020 [Press release of 19 June 2020]. Wiesbaden, Germany: Author. Retrieved from https://www.destatis.de/DE/Presse/Pressemitteilungen/2020/06/PD20_223_12411.html

Fickermann, D. \& Edelstein, B. (2020). Editorial. In D. Fickermann \& B. Edelstein (Hrsg.), „Langsam vermisse ich die Schule ...". Schule während und nach der Corona-Pandemie (S. 9-33). Münster; New York: Waxmann. doi: 10.31244/9783830992318.09

German School Barometer (2020). Retrieved from: https://deutschesschulportal.de/unterricht/das-deutsche-schulbarometer-spezial-corona-krise/

Goldan, J., Geist, S. \& Lütje-Klose, B. (2020). Schüler*innen mit sonderpädagogischem Förderbedarf während der Corona-Pandemie. In D. Fickermann \& B. Edelstein (Hrsg.), „Langsam vermisse ich die Schule ...". Schule während und nach der Corona-Pandemie (S. 189-201). Münster; New York: Waxmann. doi: 10.31244/9783830992318.09

Goodenow, C. (1993). The psychological sense of school membership among adolescents: Scale development and educational correlates. Psychology in the Schools, 30, 79-90. doi: 10.1002/1520-6807(199301)30:1<79::AID-PITS2310300113>3.0.CO;2-

Hattie, J. (2009). Visible learning. A synthesis of over 800 meta-analyses relating to achievement. London: Routledge.

Hattie, J. \& Timperley, H. (2007). The power of feedback. Review of educational Research, 77, 81-112. doi: 10.3102/003465430298487 
SCHOOL LOCKDOWN DURING COVID-19 PANDEMIC

Havighurst, R. J. (1948). Developmental tasks and education. Chicago, IL, U.S.: University of Chicago Press.

Herbert, J. \& Stipek, D. (2005). The emergence of gender differences in children's perceptions of their academic competence. Journal of Applied Developmental Psychology, 26, 276295. doi: 10.1016/j.appdev.2005.02.007

Hernández, M. M., Eisenberg, N., Valiente, C., VanSchyndel, S. K., Spinrad, T. L., Silva, K. M., Berger, R. H., Diaz, A., Terrell, N., Thompson, M. S. \& Southworth, J. (2016). Emotional expression in school context, social relationships, and academic adjustment in kindergarten. Emotion, 16(4), 553-566. doi: 10.1037/emo0000147

Hiebert, J., \& Grouws, D. A. (2007). The effects of classroom mathematics teaching on students' learning. In F. K. Lester (Ed.), Second handbook of research on mathematics teaching and learning (Vol. 1, pp. 371-404). Charlotte, NC: Information Age.

Hintsanen, M., Alatupa, S., Jokela, M., Lipsanen, J., Hintsa, T. \& Leino, M. (2012). Associations of temperament traits and mathematics grades in adolescents are dependent on the rater but independent of motivation and cognitive ability. Learning and Individual Differences, 22(4), 490-497. doi: 10.1016/j.lindif.2012.03.006

Hoffmann, I. (2020). Die Corona-Pandemie als Katalysator für Schulreformen? In D. Fickermann \& B. Edelstein (Hrsg.), „Langsam vermisse ich die Schule ...". Schule während und nach der Corona-Pandemie (S. 95-104). Münster; New York: Waxmann. doi: $10.31244 / 9783830992318.09$

Huber, S. G. \& Helm, H. (2020). Lernen in Zeiten der Corona-Pandemie. Die Rolle familiärer Merkmale für das Lernen von Schüler*innen. Befunde vom Schul-Barometer in Deutschland, Österreich und der Schweiz. In D. Fickermann \& B. Edelstein (Hrsg.), „Langsam vermisse ich die Schule ...". Schule während und nach der Corona-Pandemie (S. 37-60). Münster; New York: Waxmann. doi: 10.31244/9783830992318.09 
Hughes, J. \& Kwok, O. (2007). Influence of student-teacher and parent-teacher relationships on lower achieving readers' engagement and achievement in the primary grades. Journal of Educational Psychology, 99(1), 39-51. doi: 10.1037/0022-0663.99.1.39

Jopt, U.-J. (1978). Selbstkonzept und Ursachenerklärung in der Schule. Bochum: Kamp

Klieme, E. (2020). Guter Unterricht - auch und besonders unter Einschränkungen der Pandemie? In D. Fickermann \& B. Edelstein (Hrsg.), „Langsam vermisse ich die Schule ...". Schule während und nach der Corona-Pandemie (S. 117-135). Münster; New York: Waxmann. doi: 10.31244/9783830992318.09

Klieme, E., Pauli, C. \& Reusser, K. (2009). The Pythagoras study: investigating effects of teaching and learning in Swiss and German mathematics classrooms. In T. Janik \& T. Seidel (Eds.), The power of video studies in investigating teaching and learning in the classroom (pp. 137-160). Münster: Waxmann.

Köller, O. (2012). What works best in school? Hatties Befunde zu Effekten von Schul-und Unterrichtsvariablen auf Schulleistungen. Psychologie in Erziehung und Unterricht, 59, 72-78. doi: 10.2378/peu2012.art06d

Köller, O., Fleckenstein, J., Guill, K. \& Meyer, J. (2020). Pädagogische und didaktische Anforderungen an die häusliche Aufgabenbearbeitung. In D. Fickermann \& B. Edelstein (Hrsg.), „Langsam vermisse ich die Schule ...". Schule während und nach der CoronaPandemie (S. 163-174). Münster; New York: Waxmann. doi: $10.31244 / 9783830992318.09$

Lades, L. K., Laffan, K., Daly, M. \& Delaney, L. (2020). Daily emotional well-being during the covid-19 pandemic. British Journal of Health Psychology. doi: 10.1111/bjhp.12450

Lazarides, R. \& Buchholz, J. (2019). Student-perceived teaching quality: How is it related to different achievement emotions in mathematics classrooms? Learning and Instruction, 61, 45-59. doi: 10.1016/j.learninstruc.2019.01.001 


\section{SCHOOL LOCKDOWN DURING COVID-19 PANDEMIC}

Lorenz, C. (2011). Diagnostische Kompetenz von Grundschullehrkräften: strukturelle Aspekte und Bedingungen (Vol. 9). Bamberg: University of Bamberg Press.

Ma, X., Shen, J., Krenn, H. Y., Hu, S. \& Yuan, J. (2016). A meta-analysis of the relationship between learning outcomes and parental involvement during early childhood education and early elementary education. Educational Psychology Review, 28, 771-801. doi: $10.1007 / \mathrm{s} 10648-015-9351-1$

Maulana, R., Opdenakker, M. C. \& Bosker, R. (2016). Teachers' instructional behaviors as important predictors of academic motivation: Changes and links across the school year. Learning and Individual Differences, 50, 147-156. doi: 10.1016/j.lindif.2016.07.019

McNeish, D., Stapleton, L. M., \& Silverman, R. D. (2017). On the unnecessary ubiquity of hierarchical linear modeling. Psychological Methods, 22, 114-140. doi: $10.1037 /$ met0000078

Muthén, L. K. \& Muthén, B. O. (1998 -2015). Mplus (Version 6.12) [Computer software]. Los Angeles, CA: Author.

Niemiec, C. P. \& Ryan, R. M. (2009). Autonomy, competence, and relatedness in the classroom Applying self-determination theory to educational practice. Theory and Research in Education, 7, 133-144. doi: 10.1177/1477878509104318

Porsch, R. \& Porsch, T. (2020). Fernunterricht als Ausnahmesituation. In D. Fickermann \& B. Edelstein (Hrsg.), „Langsam vermisse ich die Schule ...". Schule während und nach der Corona-Pandemie (S. 61-78). Münster; New York: Waxmann. doi: $10.31244 / 9783830992318.09$

Praetorius, A.-K., Klieme, E., Herbert, B. \& Pinger, P. (2018). Generic dimensions of teaching quality: the German framework of Three Basic Dimensions. ZDM, 50, 407-426. doi: 10.1007/s11858-018-0918-4 
Rabbani, Z., Talepasand, S., Boogar, E. R. \& Mohammadifar, M. A. (2018). The relation of classroom instructional quality and cognitive appraisals with academic emotions and its motivational outcomes. Journal of Psychology, 22, 202-219.

Roeser, R. W., Eccles, J. S. \& Sameroff, A. J. (1998). Academic and emotional functioning in early adolescence: Longitudinal relations, patterns, and prediction by experience in middle school. Development and Psychopathology, 10, 321-352. doi:

$10.1017 / \mathrm{S} 0954579498001631$

Runge, I., Rubach, C. \& Lazarides, R. (2020). Digitale Kompetenzselbsteinschätzung von Lehrkräften - Welche Bedeutung haben Schulausstattung und Fortbildungsteilnahme angesichts aktueller Herausforderungen? In Huber, S. G. (Hrsg.), Jahrbuch Schulleitung 2021. Köln: Carl Link. Manuskript angenommen zur Veröffentlichung.

Schiepe-Tiska, A., Heine, J.-H., Lüdtke, O., Seidel, T. \& Prenzel, M. (2016).

Mehrdimensionale Bildungsziele im Mathematikunterricht und ihr Zusammenhang mit den Basisdimensionen der Unterrichtsqualität. Unterrichtswissenschaft, 44, 211-225.

Schöne, C., Dickhäuser, O., Spinath, B., \& Stiensmeier-Pelster, J. (2002). Die Skalen zur Erfassung des schulischen Selbstkonzepts (SESSKO). Göttingen: Hogrefe.

Seitz, W. \& Rausche, A. (2019). Persönlichkeitsfragebogen für Kinder zwischen 9 und 14 Jahren [Personality questionnaire for children between the age of 9 and 14] (5th Edt.). Göttingen: Hogrefe.

Šimunović, M. \& Babarović, T. (2020). The role of parents' beliefs in students' motivation, achievement, and choices in the stem domain: A review and directions for future research. Social Psychology of Education: An International Journal. doi: 10.1007/s11218020-09555-1

Sirin, S. R. (2005). Socioeconomic status and academic achievement: A meta-analytic review of research. Review of Educational Research, 75, 417-453. doi: 
Skinner, E. A., Kindermann, T. A. \& Furrer, C. J. (2008). A motivational perspective on engagement and disaffection: Conceptualization and assessment of children's behavioral and emotional participation in academic activities in the classroom. Educational and Psychological Measurement, 69, 493-525. doi: 10.1177/0013164408323233.

Sliwka, A. \& Klopsch, B. (2020). Disruptive Innovation! In D. Fickermann \& B. Edelstein (Hrsg.), „Langsam vermisse ich die Schule ...". Schule während und nach der CoronaPandemie (S. 216-229). Münster; New York: Waxmann. doi: $10.31244 / 9783830992318.09$

Stapleton, L. M., McNeish, D. M., \& Yang, J. S. (2016). Multilevel and single-level models for measured and latent variables when data are clustered. Educational Psychologist, 51, 317-330. doi: 10.1080/00461520.2016.1207178

Steinberg, L., Albert, D., Cauffman, E., Banich, M., Graham, S. \& Woolard, J. (2008). Age differences in sensation seeking and impulsivity as indexed by behavior and self-report: evidence for a dual systems model. Developmental Psychology, 44, 1764-1778. doi: $10.1037 / \mathrm{a} 0012955$

Steinmayr, R., Dinger, F. C. \& Spinath, B. (2012). Motivation as a mediator of social disparities in academic achievement. European Journal of Personality, 26, 335-349. doi: 10.1002/per.842

Steinmayr, R., Weidinger, A. F., Heyder, A. \& Bergold, S. (2019). Warum schätzen Mädchen ihre mathematischen Kompetenzen geringer ein als Jungen? - Ein Erklärungsversuch unter Berücksichtigung von Noten, Leistungstests, Lehrer- und Elterneinschätzungen. Zeitschrift für Entwicklungspsychologie und Pädagogische Psychologie, 51, 71-83. doi: $10.1026 / 0049-8637 / \mathrm{a} 000213$

Steinmayr, R., Weidinger, A. F. \& Wigfield, A. (2018). Does students' grit predict their school achievement above and beyond their personality, motivation, and engagement? 


\section{SCHOOL LOCKDOWN DURING COVID-19 PANDEMIC}

Contemporary Educational Psychology, 53, 106-122. doi:

10.1016/j.cedpsych.2018.02.004

Thorell, L, Borg-Skoglund, C., Giménez de la Peña, A., Baeyens, D., Fuermeier, A. B. M.,

Groom, M. J. et al. (under review). Psychosocial effects of homeschooling during the

COVID-19 pandemic in children with and without mental health conditions across Europe.

United for Human Rights (2020). Retrieved from

https://www.humanrights.com/course/lesson/articles-26-30/read-article-26.html

Van de Pol, J., Volman, M. \& Beishuizen, J. (2010). Scaffolding in teacher-student

interaction: A decade of research. Educational Psychology Review, 22, 271-296. doi:

$10.1007 / \mathrm{s} 10648-010-9127-6$

Vigil-Colet, A. \& Morales-Vives, F. (2005). How impulsivity is related to intelligence and academic achievement. The Spanish Journal of Psychology, 8, 199-204. doi: $10.1017 / \mathrm{S} 1138741600005072$

Voss, T. \& Wittwer, J. (2020). Unterricht in Zeiten von Corona: Ein Blick auf die Herausforderungen aus der Sicht von Unterrichts-und Instruktionsforschung. Unterrichtswissenschaft, 1-27. doi: 10.1007/s42010-020-00088-2

Wacker, A., Unger, V. \& Rey, T. (2020). „Sind doch Corona-Ferien - oder nicht?“ In D. Fickermann \& B. Edelstein (Hrsg.), ,Langsam vermisse ich die Schule ...". Schule während und nach der Corona-Pandemie (S. 79-94). Münster; New York: Waxmann. doi: $10.31244 / 9783830992318.09$

Watson, D., Clark, L. A., Chmielewski, M. \& Kotov, R. (2013). The value of suppressor effects in explicating the construct validity of symptom measures. Psychological Assessment, 25, 929-941. doi: 10.1037/a0032781

Weidinger, A. F., Spinath, B. \& Steinmayr, R. (2016). Why does intrinsic motivation decline following negative feedback? The mediating role of ability self-concept and its moderation 
SCHOOL LOCKDOWN DURING COVID-19 PANDEMIC

by goal orientations. Learning and Individual Differences, 47, 117-128. doi:

10.1016/j.lindif.2016.01.003

Wendt, H., Bos, W., Goy, M. \& Jusufi, D. (2017). TIMSS 2015. Skalenhandbuch zur

Dokumentation der Erhebungsinstrumente und Arbeit mit den Datensätzen. Münster:

Waxmann.

Wentzel, K. R. \& Miele, D. B. (2016). Handbook of Motivation in School. New York: Routledge.

Wigfield, A., Tonks, S., \& Klauda, S. L. (2016). Expectancy-value theory. In K. R. Wentzel \& D. B. Miele (Eds.), Handbook of motivation in school (2nd ed., pp. 55-74). New York: Routledge.

Wild, E., Rammert, M., \& Siegmund, A. (2006). Die Förderung selbstbestimmter Formen der Lernmotivation in Elternhaus und Schule. In M. Prenzel \& L. Allolio-Näcke (Hrsg.), Untersuchungen zur Bildungsqualität von Schule. Abschlussbericht des DFGSchwerpunktprogramms (S. 370-397). Münster: Waxmann.

Wildemann, A. \& Hosenfeld, I. (2020). Bundesweite Elternbefragung zu Homeschooling während der Covid 19-Pandemie. Erkenntnisse zur Umsetzung des Homeschoolings in Deutschland. Institut für Bildung im Kindes- und Jugendalter \& Zentrum für Empirische Pädagogische Forschung (zepf). Universität Koblenz-Landau, Campus Landau.

Wirthwein, L., Bergold, S., Preckel, F. \& Steinmayr, R. (2019). Personality and school functioning of intellectually gifted and nongifted adolescents: Self-perceptions and parents' assessments. Learning and Individual Differences, 73, 16-29. doi:

10.1016/j.lindif.2019.04.003

Wößmann, L. (2020). Folgekosten ausbleibenden Lernens: Was wir über die Coronabedingten Schulschließungen aus der Forschung lernen können. ifo Schnelldienst, 73, 3844. 
Wrase, M. (2020). Schulrechtliche Herausforderungen in Zeiten der Corona-Pandemie. In D. Fickermann \& B. Edelstein (Hrsg.), „Langsam vermisse ich die Schule ...". Schule während und nach der Corona-Pandemie (S. 105-116). Münster; New York: Waxmann. doi: $10.31244 / 9783830992318.09$ 


\section{SCHOOL LOCKDOWN DURING COVID-19 PANDEMIC}

\section{Table 1}

Frequencies and percentages of all distant teaching activities by all teachers

\begin{tabular}{|c|c|c|c|c|c|c|c|c|c|c|c|c|}
\hline \multirow[t]{2}{*}{ How often did the following teacher... } & \multicolumn{2}{|c|}{ Not yet } & \multicolumn{2}{|c|}{$\begin{array}{l}1 \text { every } 3 \\
\text { weeks }\end{array}$} & \multicolumn{2}{|c|}{$\begin{array}{l}1 \text { every } 2 \\
\text { weeks }\end{array}$} & \multicolumn{2}{|c|}{$\begin{array}{l}\text { Every } \\
\text { Week }\end{array}$} & \multicolumn{2}{|c|}{2 per week } & \multicolumn{2}{|c|}{$\begin{array}{l}3 \text { per week } \\
\text { (or more) }\end{array}$} \\
\hline & Fre. & Perc. & Fre. & Perc. & Fre. & Perc. & Fre. & Perc. & Fre. & Perc. & Fre. & Perc. \\
\hline \multicolumn{13}{|l|}{... sent tasks. } \\
\hline Math Teacher & 49 & 1.9 & 182 & 6.9 & 338 & 12.9 & 1724 & 65.6 & 183 & 7.0 & 152 & 5.8 \\
\hline Language Art Teacher & 58 & 2.2 & 188 & 7.2 & 374 & 14.2 & 1702 & 64.8 & 174 & 6.6 & 132 & 5.0 \\
\hline English Teacher & 605 & 23.0 & 195 & 7.4 & 262 & 10.0 & 1311 & 49.9 & 162 & 6.2 & 93 & 3.5 \\
\hline Biology/Science Teacher & 659 & 25.1 & 281 & 10.7 & 399 & 15.2 & 1182 & 45.0 & 65 & 2.5 & 42 & 1.6 \\
\hline \multicolumn{13}{|l|}{... sent solutions. } \\
\hline Math Teacher & 840 & 32.3 & 133 & 5.1 & 225 & 8.6 & 1181 & 45.4 & 107 & 4.1 & 118 & 4.5 \\
\hline Language Art Teacher & 1097 & 42.1 & 108 & 4.1 & 228 & 8.8 & 985 & 37.8 & 89 & 3.4 & 97 & 3.7 \\
\hline English Teacher & 1270 & 48.8 & 84 & 3.2 & 192 & 7.4 & 907 & 34.8 & 80 & 3.1 & 71 & 2.7 \\
\hline Biology/Science Teacher & 1437 & 55.2 & 128 & 4.9 & 225 & 8.6 & 730 & 28.0 & 43 & 1.7 & 41 & 1.6 \\
\hline \multicolumn{13}{|l|}{... requested students' solutions. } \\
\hline Math Teacher & 860 & 33.3 & 169 & 6.6 & 200 & 7.8 & 1126 & 43.6 & 126 & 4.9 & 99 & 3.8 \\
\hline Language Art Teacher & 805 & 31.2 & 213 & 8.3 & 250 & 9.7 & 1116 & 43.3 & 108 & 4.2 & 88 & 3.4 \\
\hline English Teacher & 1147 & 44.5 & 138 & 5.3 & 187 & 7.2 & 947 & 36.7 & 101 & 3.9 & 60 & 2.3 \\
\hline Biology/Science Teacher & 1277 & 49.5 & 164 & 6.4 & 263 & 10.2 & 795 & 30.8 & 50 & 1.9 & 31 & 1.2 \\
\hline \multicolumn{13}{|l|}{... gave feedback on students' solutions. } \\
\hline Math Teacher & 1340 & 52.5 & 224 & 8.8 & 206 & 8.1 & 645 & 25.3 & 77 & 3.0 & 61 & 2.4 \\
\hline Language Art Teacher & 1264 & 49.5 & 262 & 10.3 & 249 & 9.8 & 641 & 25.1 & 74 & 2.9 & 63 & 2.5 \\
\hline English Teacher & 1555 & 60.9 & 165 & 6.5 & 218 & 8.5 & 499 & 19.5 & 73 & 2.9 & 43 & 1.7 \\
\hline Biology/Science Teacher & 1723 & 67.5 & 170 & 6.7 & 185 & 7.2 & 408 & 16.0 & 38 & 1.5 & 28 & 1.1 \\
\hline \multicolumn{13}{|l|}{... graded students' solutions. } \\
\hline Math Teacher & 2346 & 92.5 & 54 & 2.1 & 41 & 1.6 & 78 & 3.1 & 9 & .4 & 8 & .3 \\
\hline Language Art Teacher & 2326 & 91.7 & 60 & 2.4 & 55 & 2.2 & 81 & 3.2 & 7 & .3 & 7 & .3 \\
\hline English Teacher & 2366 & 93.3 & 48 & 1.9 & 37 & 1.5 & 71 & 2.8 & 6 & .2 & 8 & .3 \\
\hline Biology/Science Teacher & 2398 & 94.6 & 44 & 1.7 & 36 & 1.4 & 50 & 2.0 & 3 & .1 & 5 & .2 \\
\hline \multicolumn{13}{|l|}{... taught via videoconference. } \\
\hline Math Teacher & 1973 & 78.1 & 121 & 4.8 & 73 & 2.9 & 272 & 10.8 & 50 & 2.0 & 38 & 1.5 \\
\hline Language Art Teacher & 2012 & 76.6 & 130 & 4.9 & 71 & 2.7 & 228 & 8.7 & 49 & 1.9 & 37 & 1.4 \\
\hline English Teacher & 2079 & 82.3 & 98 & 3.9 & 83 & 3.3 & 203 & 8.0 & 38 & 1.5 & 26 & 1.0 \\
\hline Biology/Science Teacher & 2294 & 90.8 & 48 & 1.9 & 36 & 1.4 & 108 & 4.3 & 21 & .8 & 20 & .8 \\
\hline \multicolumn{13}{|l|}{... had contact with the child. } \\
\hline Math Teacher & 1433 & 57.0 & 317 & 12.6 & 140 & 5.6 & 423 & 16.8 & 106 & 4.2 & 97 & 3.9 \\
\hline Language Art Teacher & 1354 & 53.8 & 368 & 14.6 & 176 & 7.0 & 434 & 17.2 & 98 & 3.9 & 86 & 3.4 \\
\hline English Teacher & 1660 & 66.0 & 198 & 7.9 & 130 & 5.2 & 381 & 15.1 & 78 & 3.1 & 69 & 2.7 \\
\hline Biology/Science Teacher & 1901 & 72.3 & 168 & 6.4 & 92 & 3.5 & 276 & 10.5 & 41 & 1.6 & 38 & 1.4 \\
\hline \multicolumn{13}{|l|}{... had contact with a parent. } \\
\hline Math Teacher & 1652 & 65.9 & 348 & 13.9 & 145 & 5.8 & 286 & 11.4 & 39 & 1.6 & 37 & 1.5 \\
\hline Language Art Teacher & 1572 & 62.7 & 395 & 15.8 & 158 & 6.3 & 299 & 11.9 & 44 & 1.8 & 39 & 1.6 \\
\hline English Teacher & 2003 & 79.9 & 195 & 7.8 & 93 & 3.7 & 166 & 6.6 & 29 & 1.2 & 21 & .8 \\
\hline Biology/Science Teacher & 2082 & 79.2 & 138 & 5.3 & 83 & 3.2 & 156 & 5.9 & 22 & .8 & 26 & 1.0 \\
\hline
\end{tabular}

Note. $N=2507-2628$. Freq. $=$ Frequency; Perc. $=$ valid Percent. Separate tables and figures

for elementary and secondary school samples can be found in Supplements 3-5 in the OSM. 


\section{SCHOOL LOCKDOWN DURING COVID-19 PANDEMIC}

\section{Table 2}

Means (M), Standard Deviation (SD), internal consistencies $(\alpha)$ as well as bivariate correlations for the overall sample (above the diagonal parametric, below non-parametric)

\begin{tabular}{|c|c|c|c|c|c|c|c|c|c|c|c|c|c|c|c|c|c|c|c|c|c|c|c|c|c|c|}
\hline & M & SD & $\alpha$ & 1) & 2) & 3) & 4) & 5) & 6) & 7) & 8) & 9) & 10) & 11) & 12) & 13) & 14) & 15) & 16) & 17) & 18) & 19) & 20) & 21) & 22) & 23) \\
\hline \multicolumn{27}{|l|}{$\begin{array}{l}\text { Student outcomes during the } \\
\text { school lockdown }\end{array}$} \\
\hline 1) Motivation ${ }^{b}$ & 2.70 & 1.11 & .89 & & .52 & .59 & .12 & .14 & .13 & .20 & .09 & .11 & .21 & .09 & -.30 & .42 & .15 & .17 & .04 & .04 & -.03 & -.07 & $<.01$ & .04 & .12 & .06 \\
\hline $\begin{array}{l}\text { 2) Competent and independent } \\
\text { learning } \mathrm{b}\end{array}$ & 3.17 & 1.04 & .85 & .51 & & .30 & .09 & .11 & .08 & .13 & .03 & .10 & .14 & $<-.01$ & -.31 & .37 & .28 & .29 & .11 & .01 & -.08 & -.09 & .03 & .08 & .07 & .18 \\
\hline 3) Learning Progress ${ }^{b}$ & 2.82 & 1.15 & & .57 & .29 & & .09 & .09 & .09 & .18 & .05 & .09 & .17 & .18 & -.10 & .25 & .13 & .15 & .06 & .04 & -.01 & -.02 & .08 & -.06 & .02 & -.10 \\
\hline \multicolumn{27}{|l|}{$\begin{array}{l}\text { Frequency of distant teaching } \\
\text { activities }\end{array}$} \\
\hline 4) Tasks & $3.75^{\mathrm{a}}$ & 0.89 & .76 & .12 & .10 & .08 & & .59 & .54 & .41 & .08 & .29 & .31 & -.01 & -.06 & .08 & .02 & .02 & -.02 & -.02 & -.04 & -.13 & -.04 & .17 & $<.01$ & .37 \\
\hline 5) Task Solutions ${ }^{\mathrm{c}}$ & $2.50^{\mathrm{a}}$ & 1.27 & .85 & .14 & .11 & .08 & .59 & & .42 & .47 & .11 & .35 & .31 & .03 & -.03 & .06 & .02 & .00 & -.04 & -.03 & -.06 & -.10 & -.05 & .16 & $<.01$ & .33 \\
\hline 6) Request Solutions ${ }^{c}$ & $2.75^{\mathrm{a}}$ & 1.29 & .88 & .13 & .08 & .09 & .54 & .42 & & .64 & .15 & .28 & .35 & .00 & -.06 & .04 & -.04 & .02 & -.02 & .03 & -.06 & -.10 & -.08 & .20 & $<-.01$ & .38 \\
\hline 7) Feedback ${ }^{c}$ & $1.75^{\mathrm{a}}$ & 1.18 & .85 & .19 & .13 & .16 & .41 & .47 & .64 & & .22 & .31 & .44 & .15 & -.04 & .08 & .02 & .06 & -.03 & -.01 & -.04 & -.10 & -.04 & .13 & .02 & .24 \\
\hline 8) Grading ${ }^{\mathrm{c}}$ & $1.00^{\mathrm{a}}$ & 0.58 & .92 & .07 & .02 & .03 & .08 & .11 & .15 & .22 & & .08 & .10 & .04 & -.05 & .03 & -.02 & -.01 & -.08 & .03 & .04 & .00 & -.03 & .02 & .03 & .11 \\
\hline 9) Video conference ${ }^{c}$ & $1.00^{\mathrm{a}}$ & 0.87 & .81 & .09 & .11 & .06 & .29 & .35 & .28 & .31 & .08 & & .38 & .03 & -.04 & .02 & .01 & .02 & .05 & -.04 & -.03 & -.08 & -.06 & .18 & $<.01$ & .28 \\
\hline 10) Communication Child ${ }^{c}$ & $1.50^{\mathrm{a}}$ & 1.18 & .86 & .20 & .13 & .16 & .31 & .31 & .35 & .44 & .10 & .38 & & .22 & -.04 & .08 & -.01 & .06 & .01 & -.01 & -.05 & -.14 & -.04 & .12 & .02 & .23 \\
\hline 11) Communication Parent ${ }^{c}$ & $1.00^{\mathrm{a}}$ & 0.94 & .86 & .06 & -.03 & .17 & $<-.01$ & .03 & $<.01$ & .15 & .04 & .03 & .22 & & .11 & -.03 & .03 & .00 & .00 & -.02 & .05 & -.01 & .02 & -.15 & -.02 & -.29 \\
\hline \multicolumn{27}{|l|}{ Student characteristics } \\
\hline 12) Negative emotionality ${ }^{d}$ & 3.80 & 1.26 & .84 & -.29 & -.30 & -.09 & -.06 & -.03 & -.06 & -.04 & -.05 & -.04 & -.04 & .11 & & -.26 & -.08 & -.10 & .00 & -.05 & .02 & .02 & .04 & -.09 & -.15 & -.17 \\
\hline 13) School Engagement ${ }^{d}$ & 4.08 & 1.22 & .81 & .41 & .37 & .24 & .08 & .06 & .04 & .08 & .03 & .02 & .08 & -.03 & -.26 & & .37 & .44 & .08 & .00 & -.02 & -.07 & .03 & .03 & .18 & .02 \\
\hline 14) Math competencies ${ }^{d}$ & 4.60 & 1.50 & .98 & .14 & .28 & .12 & .02 & .02 & -.04 & .02 & -.02 & $<.01$ & -.01 & .03 & -.08 & .37 & & .31 & .12 & -.01 & -.02 & -.02 & -.04 & -.02 & -.18 & -.09 \\
\hline 15) Language art competencies ${ }^{\mathrm{d}}$ & 4.82 & 1.33 & .92 & .17 & .30 & .15 & .02 & $<.01$ & .02 & .06 & $<-.01$ & .02 & .06 & $<.01$ & -.10 & .44 & .31 & & .15 & .00 & .01 & -.03 & .00 & .03 & .12 & -.04 \\
\hline \multicolumn{27}{|l|}{ Social background } \\
\hline $\begin{array}{l}\text { 16) Highest school leaving } \\
\text { certificate }\end{array}$ & 0.78 & 0.42 & & .04 & .11 & .06 & -.02 & -.04 & -.02 & -.03 & -.08 & .05 & $<.01$ & .00 & $<.01$ & .08 & .12 & .15 & & .00 & -.04 & -.05 & -.08 & .14 & .01 & -.07 \\
\hline 17) Migration background & 0.07 & 0.26 & & .04 & $<.01$ & .04 & -.02 & -.03 & .03 & -.01 & .03 & -.04 & $<-.01$ & -.02 & -.05 & $<-.01$ & -.01 & .00 & $<.01$ & & .06 & .00 & .01 & -.04 & .01 & .00 \\
\hline
\end{tabular}




\section{SCHOOL LOCKDOWN DURING COVID-19 PANDEMIC}

\begin{tabular}{|c|c|c|c|c|c|c|c|c|c|c|c|c|c|c|c|c|c|c|c|c|c|c|c|c|c|}
\hline 18) Child has an own room & 0.91 & 0.29 & .03 & .08 & $<.01$ & .04 & .06 & .06 & .04 & -.04 & .03 & .05 & -.05 & -.02 & $<.01$ & .02 & -.01 & .04 & -.06 & & -.10 & $\begin{array}{l}<- \\
.01\end{array}$ & .17 & $<.01$ & .12 \\
\hline 19) Child has a computer/tablet & 0.93 & 0.26 & .08 & .09 & .03 & .13 & .10 & .10 & .10 & $<.01$ & .08 & .14 & $<.01$ & -.02 & .07 & .02 & .03 & .05 & .00 & -.10 & & -.03 & .11 & $<-.01$ & .17 \\
\hline \multicolumn{26}{|l|}{$\begin{array}{l}\text { Child's and parent's gender and } \\
\text { age }\end{array}$} \\
\hline 20) Parent's gender & 0.85 & 0.38 & -.01 & .03 & .07 & -.04 & -.05 & -.07 & -.03 & -.01 & -.07 & -.02 & .02 & .04 & .02 & -.04 & .00 & -.08 & .01 & $<.01$ & .03 & & -.19 & .08 & -.03 \\
\hline 21) Parent's age & 43.37 & 5.66 & .04 & .08 & -.07 & .17 & .16 & .20 & .13 & .02 & .18 & .12 & -.15 & -.09 & .03 & -.02 & .03 & .14 & -.04 & -.17 & -.11 & -.19 & & .01 & .43 \\
\hline 22) Child's gender & 0.52 & 0.59 & .12 & .07 & .02 & $<.01$ & $<.01$ & $<.01$ & .02 & .03 & .03 & .03 & -.03 & -.16 & .18 & -.19 & .13 & .01 & .01 & $<-.01$ & $<.01$ & .08 & .02 & & -.01 \\
\hline 23) Child's age & 10.84 & 2.70 & .06 & .17 & -.11 & .37 & .33 & .38 & .25 & .13 & .28 & .23 & -.29 & -.17 & .02 & -.09 & -.04 & -.07 & $<-.01$ & -.12 & -.17 & -.03 & .43 & -.01 & \\
\hline
\end{tabular}

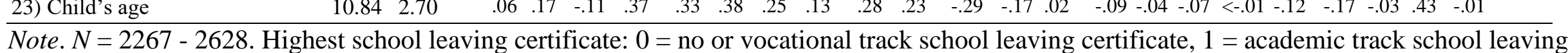

certificate; Child has an own bedroom: $0=$ no, $1=$ yes; Child has a computer/tablet: $0=$ no, $1=$ yes; Gender: $0=$ male, $1=$ female; migration

background: $0=$ no, $1=$ yes. Separate tables for the elementary and secondary school samples can be found in Supplements 6 and 7 in the OSM.

${ }^{\mathrm{a}}$ The median was reported instead of the mean as the scores were skewed.

${ }^{\mathrm{b}}$ Scale ranged from 1 to 5 .

${ }^{\mathrm{c} S}$ Scale ranged from 1 to 6.

${ }^{\mathrm{d}}$ Scale ranged from 1 to 7.

Correlations: $r<.04 p<.05, r<.05 p<.01,, r<.06 p<.001$. 


\section{SCHOOL LOCKDOWN DURING COVID-19 PANDEMIC}

\section{Table 3}

Model Fit indices and inter-correlations between exogenous variables for SEMs regressing distant teaching activities and students' characteristics on students' academic outcomes during the school lockdown for the total sample (All), elementary school (ES) and secondary $\operatorname{school}(\mathrm{Sec})$

\begin{tabular}{rlllllll}
\hline & $\chi^{2}(\mathrm{df})$ & RMSEA (CI 90\%) & CFI & TLI & $\mathrm{r}_{\text {resM x resC }}$ & $\mathrm{r}_{\text {resM x resL }}$ & $\mathrm{r}_{\text {resC x resL }}$ \\
\hline All & $1663.54(1290)$ & $.011(.009-.012)$ & .988 & .984 & .548 & .594 & .375 \\
ES & $1388.99(1290)$ & $.009(.003-.012)$ & .994 & .992 & .497 & .567 & .300 \\
Sec & $1470.11(1290)$ & $.010(.007-.012)$ & .988 & .984 & .546 & .611 & .267
\end{tabular}

Note. resM $=$ residual factor motivation. resC $=$ residual factor competent and independent learning. resL $=$ residual learning process. $\mathrm{df}=$ degrees of freedom $. \mathrm{CI}=$ Confidence Interval 


\section{SCHOOL LOCKDOWN DURING COVID-19 PANDEMIC}

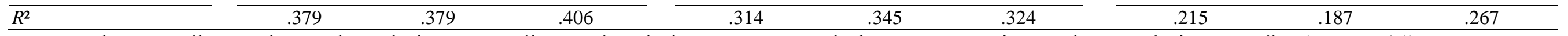

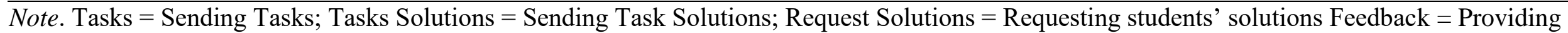
feedback on students' solutions; Video = Teaching via videoconference; Com. Child = Student-teacher communication; Com. Parent = parentteacher communication; Neg. emotionality = negative emotionality; Engagement = school engagement; Math competence = competencies in math;

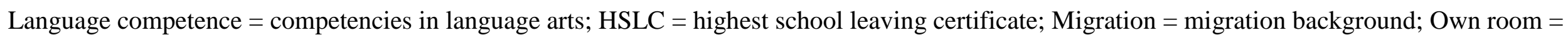
Child has an own bedroom; Computer = Child has a computer/tablet during the school lockdown. Highest school leaving certificate: $0=$ no or vocational track school leaving certificate, $1=$ academic track school leaving certificate; migration background: $0=$ no, $1=$ yes; Child has an own bedroom: $0=$ no, 1 = yes; Child has a computer/tablet: $0=$ no, $1=$ yes; Gender: $0=$ male, $1=$ female.

$* p<.05, * * p<.01, * * * p<.001$. 


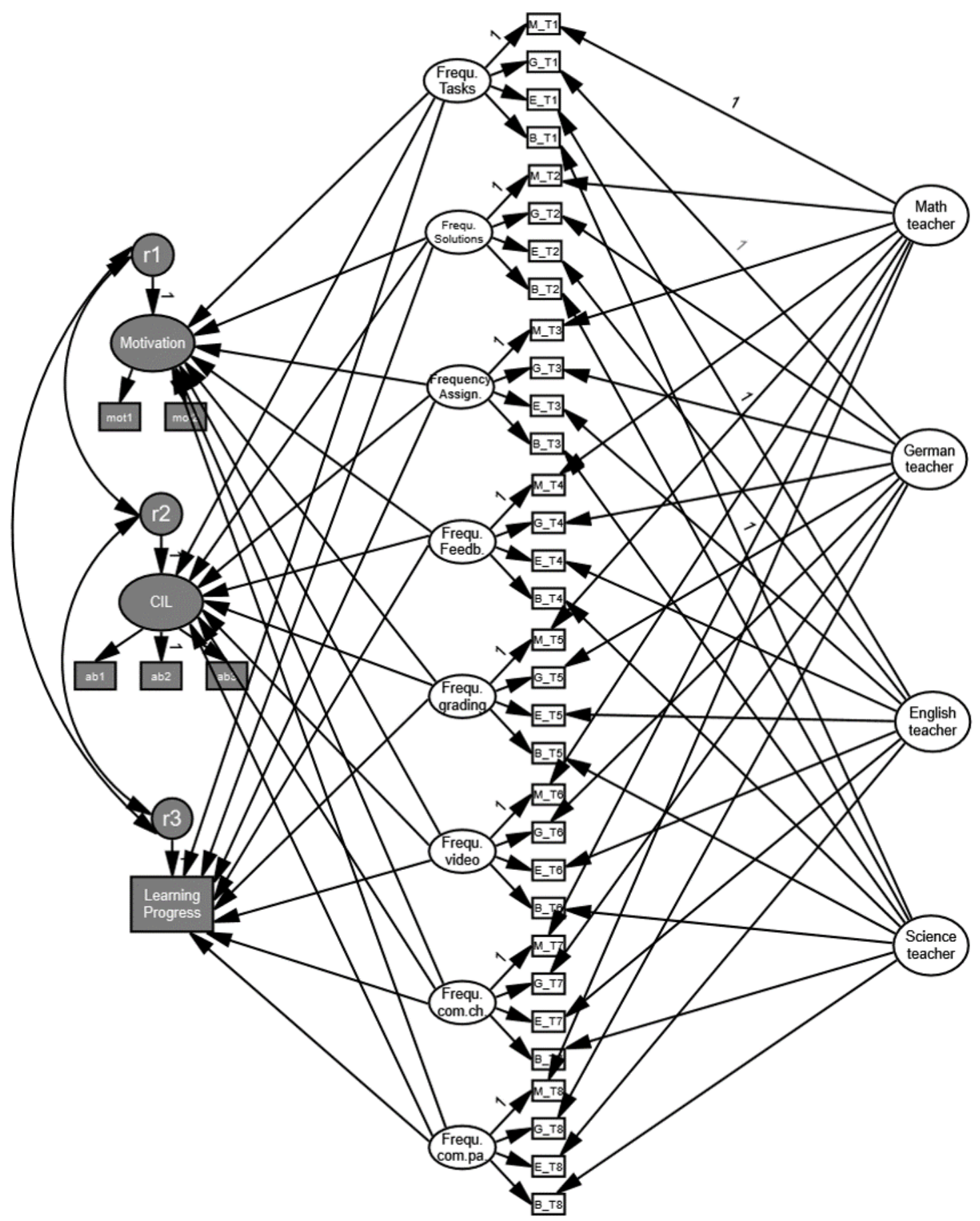

Figure 1. SEM regressing teachers' distant teaching activities on students' motivation (Motivation), competent and independent learning (CIL) and learning progress (Learning Progress) during school lockdown. Measurement model of the distant teaching activities covers all variables with a white background. Frequ. = Frequency of the distant teaching activity; Tasks $=$ sending tasks; Solutions $=$ sending solutions for the tasks; Assign.$=$ 
requesting students' solutions; Feedb. = giving feedback on students' solutions; Grading = grading students' solutions; Video = teaching via videoconference; Com.Ch. $=$ having contact with their child via chat, e-mail or phone; Com.Pa. = having contact with a parent via chat, email or phone. All distant teaching activities were correlated and all teacher factors were correlated. Correlation and measurement errors are not displayed to ensure a clearer depiction of the measurement model. For the same reason, students' and family's characteristics were not displayed. 


\section{Online Supplemental Material}

Teaching and Learning During the COVID-19 School Lockdown: Realization and Associations with Parent-Perceived Students' Academic Outcomes-A study and preliminary overview

by [blinded for peer review], submitted, Zeitschrift für Pädagogische Psychologie

\section{Overview}

Supplement 1. Further information on the sample

Supplement 2. Description how the distant teaching activities were modelled

Supplement 3. Frequencies and percentages of all distant teaching activities by elementary school teachers

Supplement 4. Frequencies and percentages of all distant teaching activities by secondary school teachers

Supplement 5. Figures depicting the frequencies of all distant teaching activities by elementary and secondary school teachers

Supplement 6. Descriptive statistics for the elementary school sample

Supplement 7. Descriptive statistics for the secondary school sample

Supplement 8. Model fit of structure equation models without student characteristics and demographics as additional predictors 
Supplement 9. Results of structure equation models without student characteristics and demographics as additional predictors 


\section{Supplement 1. Further information on the sample}

The majority of the study's participants ( $44.8 \%$ ) was from North-Rhine-Westphalia, $18.5 \%$ of parents were from Lower Saxony, $11.9 \%$ from Baden-Wuerttemberg, $4.6 \%$ from Bavaria, 3.9 \% from Hesse, $3.1 \%$ from Rhineland-Palatinate, $2.6 \%$ from Schleswig-Holstein, $2.6 \%$ from Thuringia, $2.0 \%$ from Berlin, 1.7 \% from Saxony, $0.9 \%$ from Mecklenburg-Western Pomerania, $0.6 \%$ from Brandenburg. $0.6 \%$ from Saxony-Anhalt, $0.5 \%$ from Hamburg, and $0.5 \%$ from Saarland.

Parents indicated that their children attended the following schools: $40.2 \%$ of all children attended elementary schools, $37.5 \%$ academic track secondary schools ("Gymnasium"), $8.8 \%$ comprehensive secondary schools ("Gesamtschule"), $7.9 \%$ intermediate track secondary schools ("Realschule"), 0.8 \% lowest track secondary schools ("Hauptschule"), $0.6 \%$ schools for special educational needs ("Förderschule"), and $4.1 \%$ another school type.

Parents indicated that their children attended the following grades: Grade 1: 9.2\%; Grade 2: $10.0 \%$; Grade 3: $11.6 \%$; Grade 4: $9.6 \%$; Grade 5: $16.4 \%$; Grade 6: $12.6 \%$; Grade 7: $11.0 \%$; Grade 8: $6.8 \%$; Grade 9: $6.6 \%$; Grade 10: $2.6 \%$; Grade 11: $1.7 \%$; Grade 12: $0.6 \%$; Grade 13: $0.2 \%)$. 


\section{Supplement 2. Description how the distant teaching activities were modelled}

The measurement model for distant teaching activities were set up the following way: items with the same word stem rated for teachers in different subjects (math, language arts, English, science/biology) were regressed on a factor indicating how often this distant teaching activity over different subjects was realized in the class that the student attended. In all federal states, it was up to the schools to decide how to realize distant teaching. Thus, all activities were correlated as it might be assumed that at one school the principal and/or the teachers agreed on which distant teaching activities had to be realized. Furthermore, four additional latent factors indicating the four subject teachers were modeled. All distant teaching activities that one teacher realized were regressed on the corresponding teacher factor. Beside the schools' decision on how to realize distant teaching it might well be that some teachers were more engaged in the realization of distant teaching than others. This potential additional variance was captured by these teacher factors. We explicitly asked parents to rate each subject, even if one teacher taught more than one subject, which is especially likely in elementary school but also happens in secondary school. Thus, we correlated the teacher factors in order to control for this (s. Figure 1 in the manuscript). We also tested a hierarchical model with a general distant teaching activities factor indicated by all single distant teaching activities. The model fit did not differ from the measurement model depicted in Figure 1. As we were primarily interested in how each distant teaching activity and not a general distant teaching activity factor was associated with students' motivation, competent and independent learning, and learning progress during the school lockdown, we decided to model distant teaching activities as described above. 


\section{Supplement 3. Frequencies and percentages of all distant teaching activities by elementary school}

\section{teachers}

\section{Table S3}

Frequencies and percentages of all distant teaching activities by elementary school teachers

\begin{tabular}{|c|c|c|c|c|c|c|c|c|c|c|c|c|}
\hline \multirow[t]{2}{*}{ How often did the following teacher... } & \multicolumn{2}{|c|}{ Not yet } & \multicolumn{2}{|c|}{$\begin{array}{l}1 \text { every } 3 \\
\text { weeks }\end{array}$} & \multicolumn{2}{|c|}{$\begin{array}{l}1 \text { every } 2 \\
\text { weeks }\end{array}$} & \multicolumn{2}{|c|}{ Every Week } & \multicolumn{2}{|c|}{2 per week } & \multicolumn{2}{|c|}{$\begin{array}{l}3 \text { per week } \\
\text { (or more) }\end{array}$} \\
\hline & Fre. & Perc. & Fre. & Perc. & Fre. & Perc. & Fre. & Perc. & Fre. & Perc. & Fre. & Perc. \\
\hline \multicolumn{13}{|l|}{... send tasks. } \\
\hline Math Teacher & 22 & 2.1 & 94 & 8.8 & 199 & 18.7 & 678 & 63.8 & 26 & 2.4 & 44 & 4.1 \\
\hline Language Art Teacher & 25 & 2.4 & 95 & 8.9 & 191 & 18.0 & 683 & 64.3 & 27 & 2.5 & 42 & 4.0 \\
\hline English Teacher & 563 & 53.0 & 120 & 11.3 & 93 & 8.7 & 271 & 25.5 & 6 & .6 & 10 & .9 \\
\hline Biology/Science Teacher & 434 & 40.8 & 118 & 11.1 & 127 & 11.9 & 364 & 34.2 & 10 & .9 & 10 & .9 \\
\hline \multicolumn{13}{|l|}{... send solutions. } \\
\hline Math Teacher & 550 & 52.2 & 47 & 4.5 & 77 & 7.3 & 316 & 30.0 & 16 & 1.5 & 48 & 4.6 \\
\hline Language Art Teacher & 564 & 53.5 & 49 & 4.6 & 77 & 7.3 & 313 & 29.7 & 13 & 1.2 & 38 & 3.6 \\
\hline English Teacher & 824 & 78.2 & 30 & 2.8 & 39 & 3.7 & 147 & 13.9 & 2 & .2 & 12 & 1.1 \\
\hline Biology/Science Teacher & 761 & 72.2 & 37 & 3.5 & 51 & 4.8 & 180 & 17.1 & 7 & .7 & 18 & 1.7 \\
\hline \multicolumn{13}{|l|}{... requested students' solutions. } \\
\hline Math Teacher & 497 & 47.5 & 90 & 8.6 & 98 & 9.4 & 305 & 29.2 & 20 & 1.9 & 36 & 3.4 \\
\hline Language Art Teacher & 450 & 43.0 & 105 & 10.0 & 106 & 10.1 & 331 & 31.6 & 21 & 2.0 & 33 & 3.2 \\
\hline English Teacher & 792 & 75.7 & 42 & 4.0 & 44 & 4.2 & 150 & 14.3 & 9 & .9 & 9 & .9 \\
\hline Biology/Science Teacher & 701 & 67.0 & 60 & 5.7 & 78 & 7.5 & 187 & 17.9 & 10 & 1.0 & 10 & 1.0 \\
\hline \multicolumn{13}{|l|}{... gave feedback on students' solutions. } \\
\hline Math Teacher & 613 & 59.4 & 101 & 9.8 & 80 & 7.8 & 196 & 19.0 & 18 & 1.7 & 24 & 2.3 \\
\hline Language Art Teacher & 565 & 54.7 & 120 & 11.6 & 89 & 8.6 & 211 & 20.4 & 20 & 1.9 & 27 & 2.6 \\
\hline English Teacher & 859 & 83.2 & 38 & 3.7 & 39 & 3.8 & 79 & 7.7 & 9 & .9 & 8 & .8 \\
\hline Biology/Science Teacher & 784 & 76.0 & 63 & 6.1 & 61 & 5.9 & 101 & 9.8 & 12 & 1.2 & 11 & 1.1 \\
\hline
\end{tabular}

... graded students' solutions. 


\begin{tabular}{|c|c|c|c|c|c|c|c|c|c|c|c|c|}
\hline Math Teacher & 957 & 93.4 & 19 & 1.9 & 17 & 1.7 & 28 & 2.7 & 4 & .4 & & \\
\hline Language Art Teacher & 947 & 92.4 & 27 & 2.6 & 19 & 1.9 & 29 & 2.8 & 3 & .3 & & \\
\hline English Teacher & 987 & 96.3 & 12 & 1.2 & 6 & 6 & 19 & 1.9 & 1 & .1 & & \\
\hline Biology/Science Teacher & 983 & 95.9 & 14 & 1.4 & 9 & .9 & 17 & 1.7 & 2 & .2 & & \\
\hline \multicolumn{13}{|c|}{... taught via video conference. } \\
\hline Math Teacher & 912 & 89.2 & 32 & 3.1 & 11 & 1.1 & 50 & 4.9 & 7 & .7 & 10 & 1.0 \\
\hline Language Art Teacher & 886 & 86.7 & 53 & 5.2 & 11 & 1.1 & 51 & 5.0 & 10 & 1.0 & 11 & 1.1 \\
\hline English Teacher & 977 & 95.6 & 10 & 1.0 & 8 & .8 & 16 & 1.6 & 5 & .5 & 6 & .6 \\
\hline Biology/Science Teacher & 979 & 95.8 & 10 & 1.0 & 7 & .7 & 16 & 1.6 & 4 & .4 & 6 & .6 \\
\hline \multicolumn{13}{|c|}{... had contact with their child. } \\
\hline Math Teacher & 646 & 63.5 & 155 & 15.2 & 54 & 5.3 & 119 & 11.7 & 22 & 2.2 & 22 & 2.2 \\
\hline Language Art Teacher & 570 & 56.0 & 207 & 20.3 & 70 & 6.9 & 122 & 12.0 & 26 & 2.6 & 23 & 2.3 \\
\hline English Teacher & 877 & 86.1 & 47 & 4.6 & 24 & 2.4 & 53 & 5.2 & 9 & .9 & 8 & .8 \\
\hline Biology/Science Teacher & 810 & 79.6 & 80 & 7.9 & 28 & 2.8 & 77 & 7.6 & 12 & 1.2 & 11 & 1.1 \\
\hline \multicolumn{13}{|c|}{... had contact with a parent. } \\
\hline Math Teacher & 497 & 49.1 & 204 & 20.1 & 83 & 8.2 & 184 & 18.2 & 25 & 2.5 & 20 & 2.0 \\
\hline Language Art Teacher & 439 & 43.3 & 225 & 22.2 & 92 & 9.1 & 205 & 20.2 & 30 & 3.0 & 22 & 2.2 \\
\hline English Teacher & 823 & 81.2 & 67 & 6.6 & 36 & 3.6 & 68 & 6.7 & 13 & 1.3 & 6 & .6 \\
\hline Biology/Science Teacher & 742 & 73.2 & 84 & 8.3 & 50 & 4.9 & 107 & 10.6 & 15 & 1.5 & 15 & 1.5 \\
\hline
\end{tabular}

Notes. $N=$ 1063. Freq. $=$ Frequency. Perc. $=$ valid Percent. 


\section{Supplement 4. Frequencies and percentages of all distant teaching activities by secondary school}

\section{teachers}

\section{Table S4}

Frequencies and percentages of all distant teaching activities by teachers at a Gymnasisum (academic track), Realschule (intermediate track), Hauptschulde (lowest track), and Gesamtschule (comprehensive school)

\begin{tabular}{|c|c|c|c|c|c|c|c|c|c|c|c|c|}
\hline \multirow[t]{2}{*}{ How often did the following teacher... } & \multicolumn{2}{|c|}{ Not yet } & \multicolumn{2}{|c|}{$\begin{array}{l}1 \text { every } 3 \\
\text { weeks }\end{array}$} & \multicolumn{2}{|c|}{$\begin{array}{l}1 \text { every } 2 \\
\text { weeks }\end{array}$} & \multicolumn{2}{|c|}{ Every Week } & \multicolumn{2}{|c|}{2 per week } & \multicolumn{2}{|c|}{$\begin{array}{l}3 \text { per week } \\
\text { (or more) }\end{array}$} \\
\hline & Fre. & Perc. & Fre. & Perc. & Fre. & Perc. & Fre. & Perc. & Fre. & Perc. & Fre. & Perc. \\
\hline \multicolumn{13}{|l|}{... send tasks. } \\
\hline Math Teacher & 21 & 1.4 & 78 & 5.4 & 125 & 8.6 & 987 & 67.8 & 151 & 10.4 & 94 & 6.5 \\
\hline Language Art Teacher & 25 & 1.7 & 84 & 5.8 & 167 & 11.5 & 958 & 65.8 & 144 & 9.9 & 78 & 5.4 \\
\hline English Teacher & 27 & 1.9 & 69 & 4.7 & 154 & 10.6 & 976 & 67.0 & 152 & 10.4 & 78 & 5.4 \\
\hline Biology/Science Teacher & 193 & 13.3 & 152 & 10.4 & 259 & 17.8 & 775 & 53.2 & 52 & 3.6 & 25 & 1.7 \\
\hline \multicolumn{13}{|l|}{... send solutions. } \\
\hline Math Teacher & 254 & 17.6 & 79 & 5.5 & 141 & 9.8 & 818 & 56.7 & 89 & 6.2 & 62 & 4.3 \\
\hline Language Art Teacher & 493 & 34.2 & 54 & 3.7 & 144 & 10.0 & 629 & 43.6 & 73 & 5.1 & 50 & 3.5 \\
\hline English Teacher & 402 & 27.9 & 53 & 3.7 & 141 & 9.8 & 718 & 49.8 & 74 & 5.1 & 55 & 3.8 \\
\hline Biology/Science Teacher & 620 & 43.0 & 85 & 5.9 & 166 & 11.5 & 520 & 36.0 & 34 & 2.4 & 18 & 1.2 \\
\hline \multicolumn{13}{|l|}{... requested students' solutions. } \\
\hline Math Teacher & 341 & 23.9 & 70 & 4.9 & 94 & 6.6 & 766 & 53.7 & 101 & 7.1 & 55 & 3.9 \\
\hline Language Art Teacher & 327 & 22.9 & 103 & 7.2 & 137 & 9.6 & 731 & 51.2 & 81 & 5.7 & 48 & 3.4 \\
\hline English Teacher & 322 & 22.6 & 94 & 6.6 & 132 & 9.3 & 747 & 52.3 & 85 & 6.0 & 47 & 3.3 \\
\hline Biology/Science Teacher & 529 & 37.1 & 99 & 6.9 & 175 & 12.3 & 569 & 39.9 & 36 & 2.5 & 19 & 1.3 \\
\hline \multicolumn{13}{|l|}{... gave feedback on students' solutions. } \\
\hline Math Teacher & 671 & 47.4 & 116 & 8.2 & 121 & 8.6 & 420 & 29.7 & 55 & 3.9 & 32 & 2.3 \\
\hline Language Art Teacher & 648 & 45.8 & 137 & 9.7 & 152 & 10.7 & 397 & 28.1 & 52 & 3.7 & 29 & 2.0 \\
\hline
\end{tabular}


English Teacher

Biology/Science Teacher $\begin{array}{lll}636 & 44.9 \quad 123\end{array}$

87
$61.5 \quad 100 \quad 7.1$
$8.7 \quad 172$

12.2393

$27.8 \quad 59$

$4.2 \quad 32$

19 $\begin{array}{llll}8.4 & 287 & 20.3 & 2\end{array}$

... graded students' solutions.

Math Teacher

Language Art Teacher

English Teacher

Biology/Science Teacher

$\begin{array}{llllllllllll}1297 & 92.2 & 30 & 2.1 & 22 & 1.6 & 46 & 3.3 & 5 & .4 & 6 & .4 \\ 1287 & 91.5 & 31 & 2.2 & 29 & 2.1 & 50 & 3.6 & 4 & .3 & 5 & .4 \\ 1286 & 91.5 & 32 & 2.3 & 28 & 2.0 & 49 & 3.5 & 5 & .4 & 6 & .4 \\ 1316 & 93.6 & 28 & 2.0 & 25 & 1.8 & 33 & 2.3 & 1 & .1 & 3 & .2\end{array}$

... taught via videoconference.

Math Teacher

$\begin{array}{lllllllllllll}982 & 70.1 & 84 & 6.0 & 60 & 4.3 & 211 & 15.1 & 39 & 2.8 & 24 & 1.7 \\ 1045 & 74.6 & 72 & 5.1 & 57 & 4.1 & 169 & 12.1 & 36 & 2.6 & 21 & 1.5 \\ 1028 & 73.4 & 81 & 5.8 & 66 & 4.7 & 177 & 12.6 & 31 & 2.2 & 17 & 1.2 \\ 1223 & 87.4 & 35 & 2.5 & 27 & 1.9 & 87 & 6.2 & 16 & 1.1 & 12 & .9\end{array}$

Biology/Science Teacher

Language Art Teacher

English Teacher

... had contact with their child.

Math Teacher

Language Art Teacher

English Teacher

Biology/Science Teacher

$\begin{array}{llllllllllll}737 & 52.9 & 140 & 10.0 & 81 & 5.8 & 287 & 20.6 & 80 & 5.7 & 69 & 4.9 \\ 736 & 52.8 & 142 & 10.2 & 100 & 7.2 & 292 & 20.9 & 67 & 4.8 & 57 & 4.1 \\ 726 & 52.1 & 138 & 9.9 & 100 & 7.2 & 311 & 22.3 & 62 & 4.4 & 57 & 4.1 \\ 1020 & 73.2 & 74 & 5.3 & 62 & 4.4 & 187 & 13.4 & 27 & 1.9 & 24 & 1.7\end{array}$

... had contact with a parent.

Math Teacher $\begin{array}{llllllllllll}1092 & 78.6 & 130 & 9.4 & 54 & 3.9 & 90 & 6.5 & 11 & .8 & 13 & .9\end{array}$

Language Art Teacher

English Teacher $\begin{array}{llllllllllll}1072 & 77.1 & 159 & 11.4 & 59 & 4.2 & 77 & 5.5 & 10 & .7 & 13 & .9\end{array}$ $\begin{array}{llllllllllll}1106 & 79.6 & 122 & 8.8 & 51 & 3.7 & 84 & 6.0 & 16 & 1.2 & 11 & .8\end{array}$ $\begin{array}{llllllllllll}1260 & 90.6 & 50 & 3.6 & 28 & 2.0 & 40 & 2.9 & 4 & .3 & 8 & .6\end{array}$

Biology/Science Teacher

Notes. $N=$ 1456. Freq. $=$ Frequency. Perc. $=$ valid Percent. 
Supplement 5. Figures depicting the frequencies of all distant teaching activities by elementary and secondary school teachers
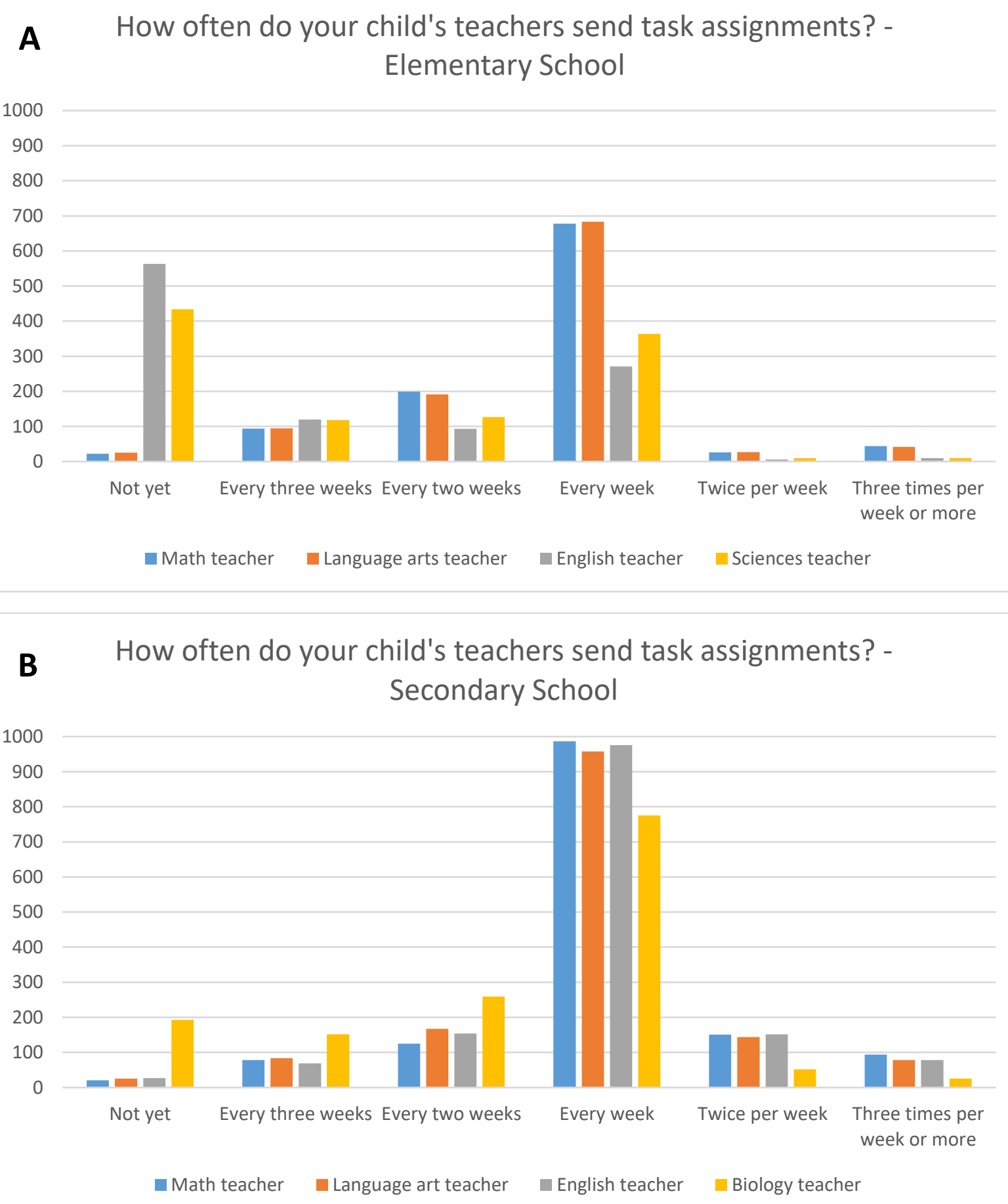

Figure S5.1. Frequencies of sending task assignments in elementary school (A) and secondary school (B). 

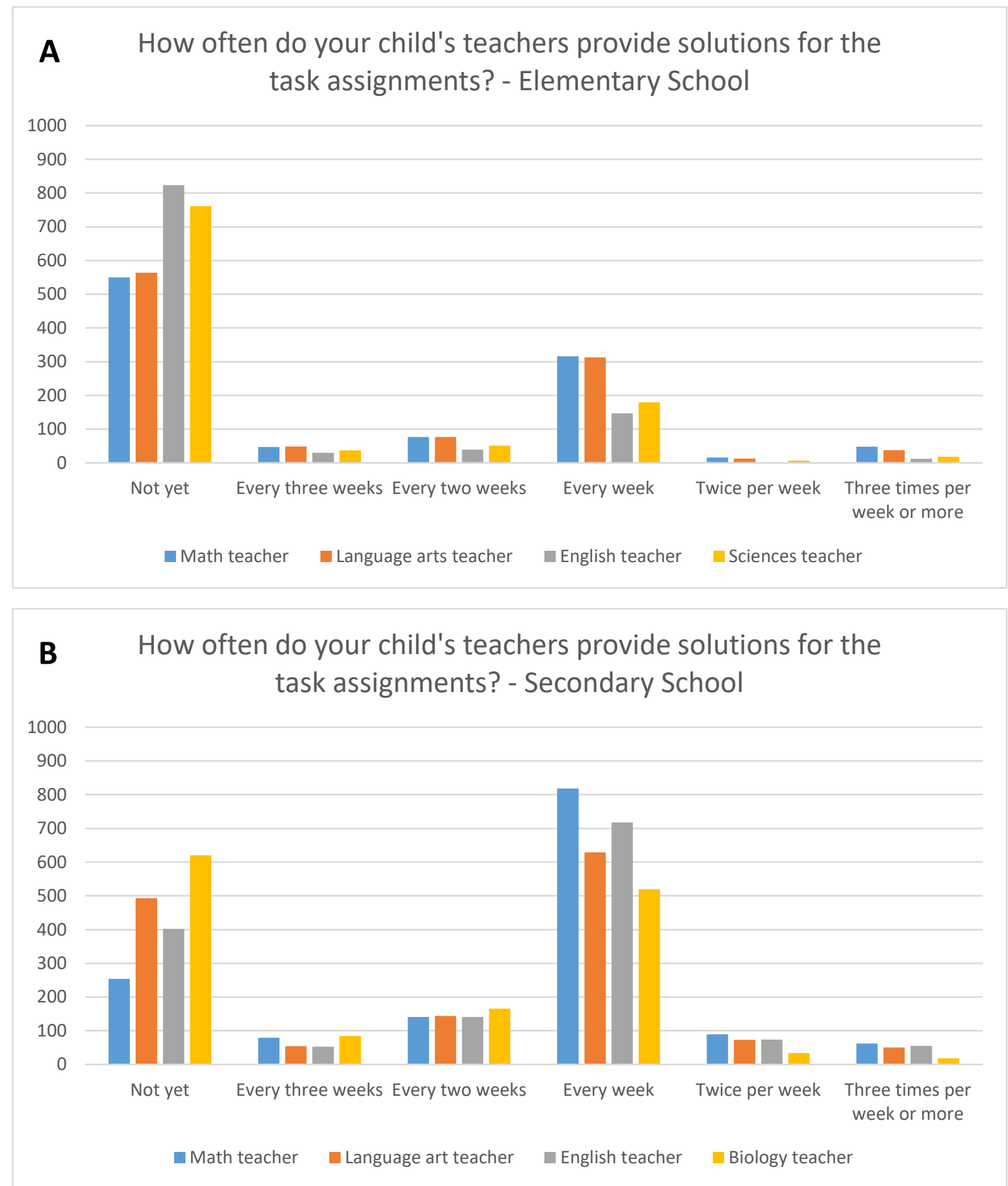

Figure S5.2. Frequencies of providing solutions for the task assignments in elementary school (A) and secondary school (B). 

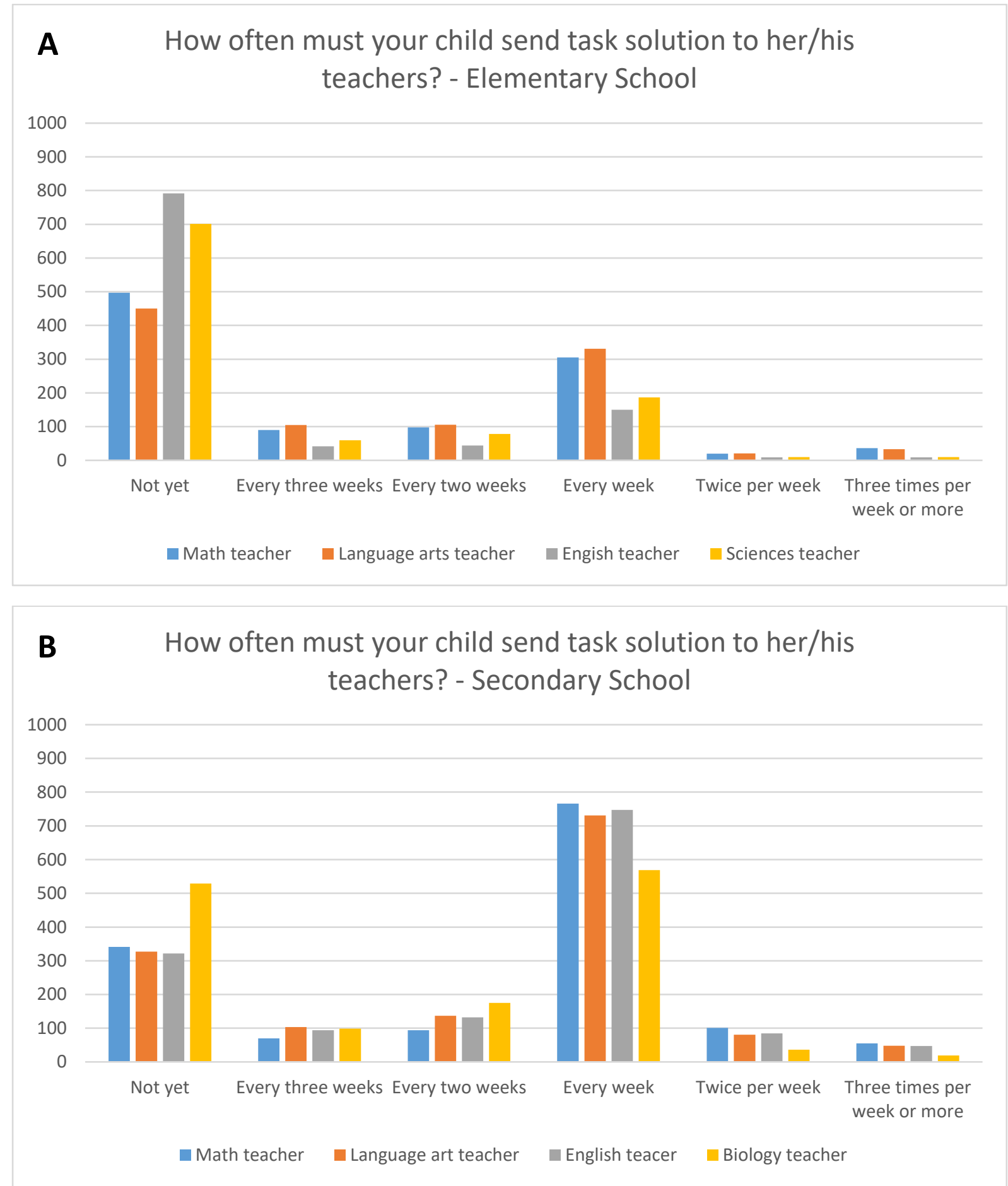

Figure S5.3. Frequencies of requesting solutions for the task assignments from the students in elementary school (A) and secondary school (B). 

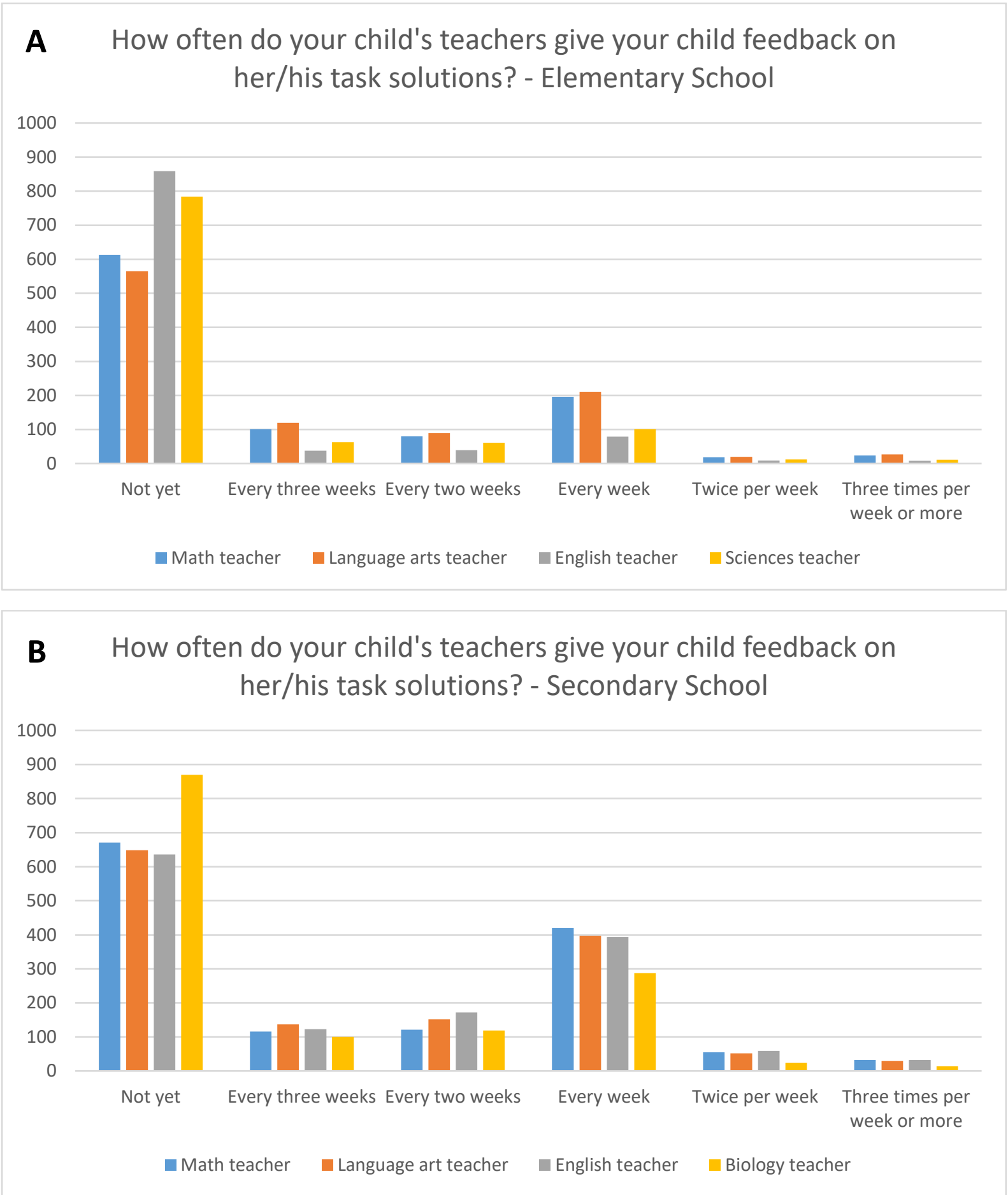

Figure S5.4. Frequencies of giving feedback on the students' task solutions in elementary school (A) and secondary school (B). 

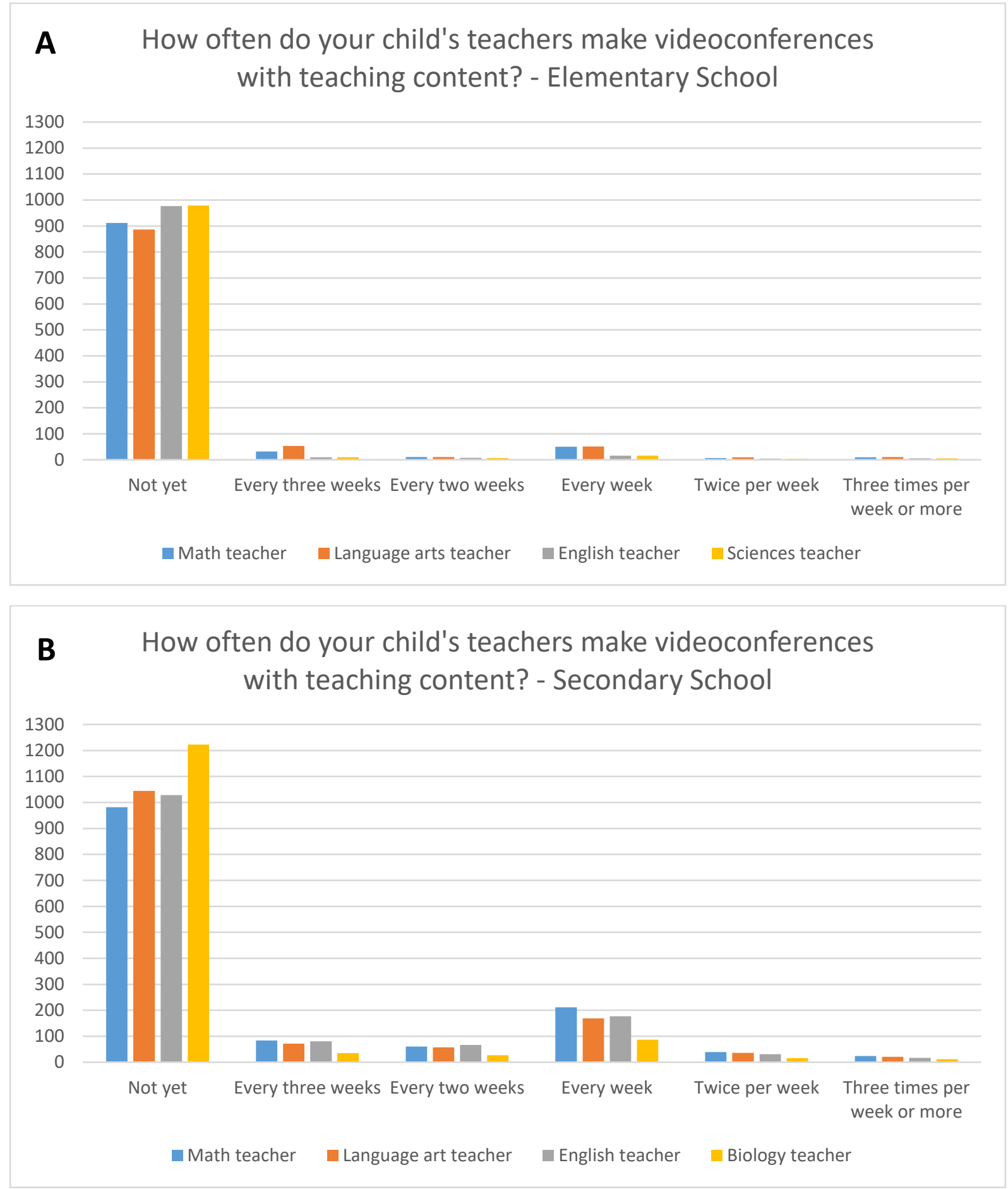

Figure S5.5. Frequencies of making videoconferences with teaching content in elementary school (A) and secondary school (B). 


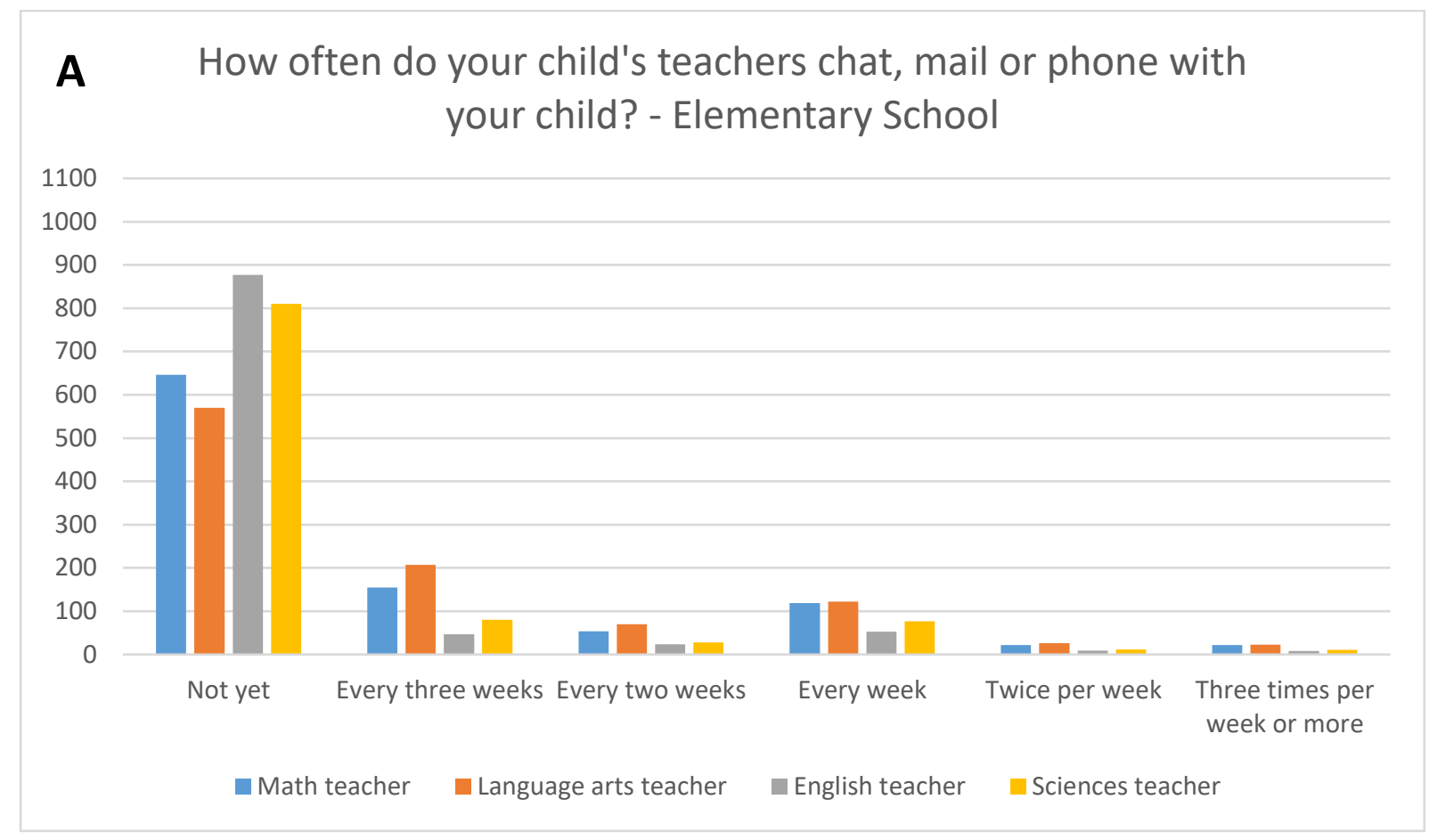

\section{B How often do your child's teachers chat, mail or phone with your child? - Secondary School}

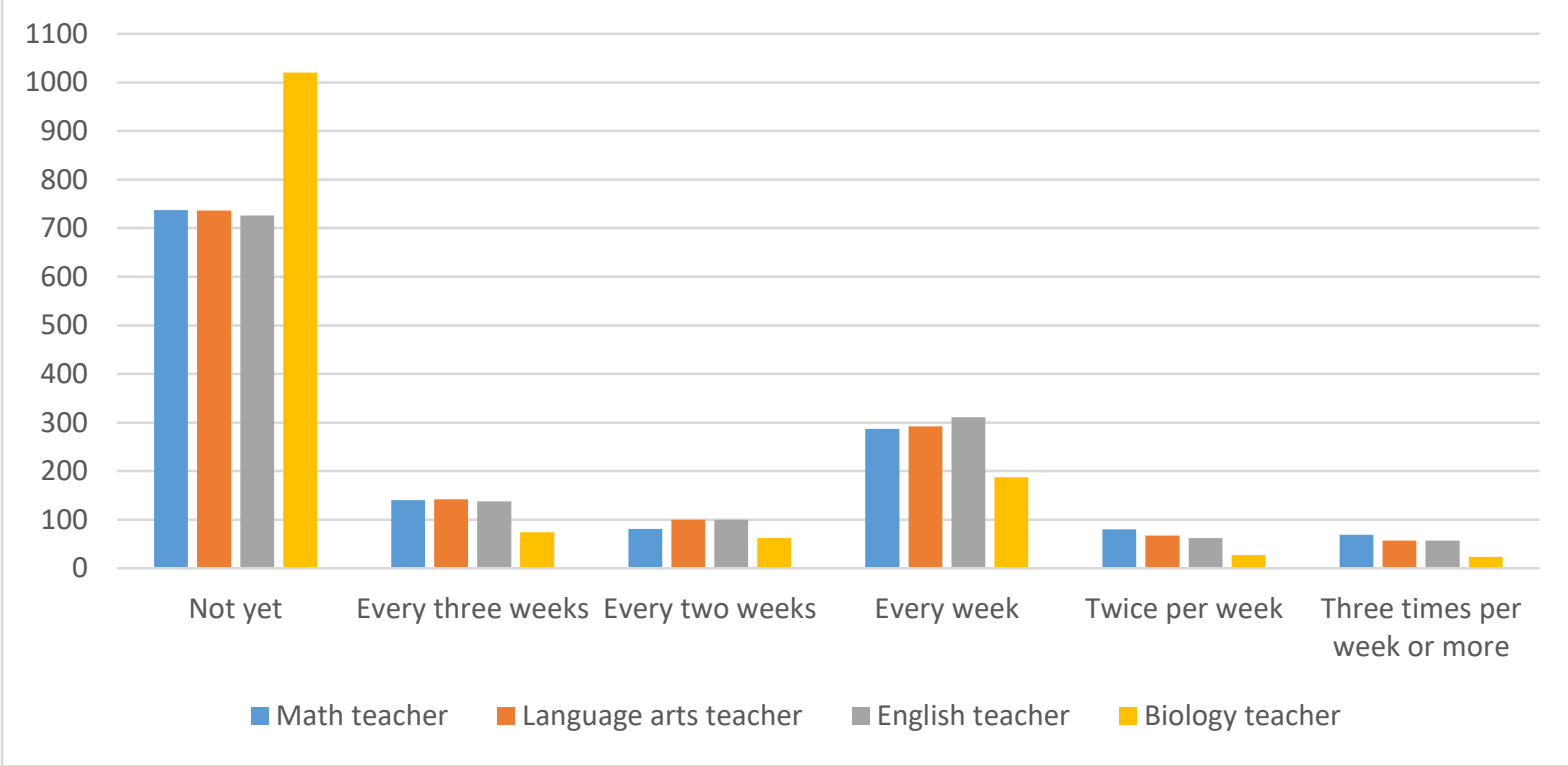

Figure S5.6. Frequencies of chatting, mailing or phoning with the students in elementary school (A) and secondary school (B). 

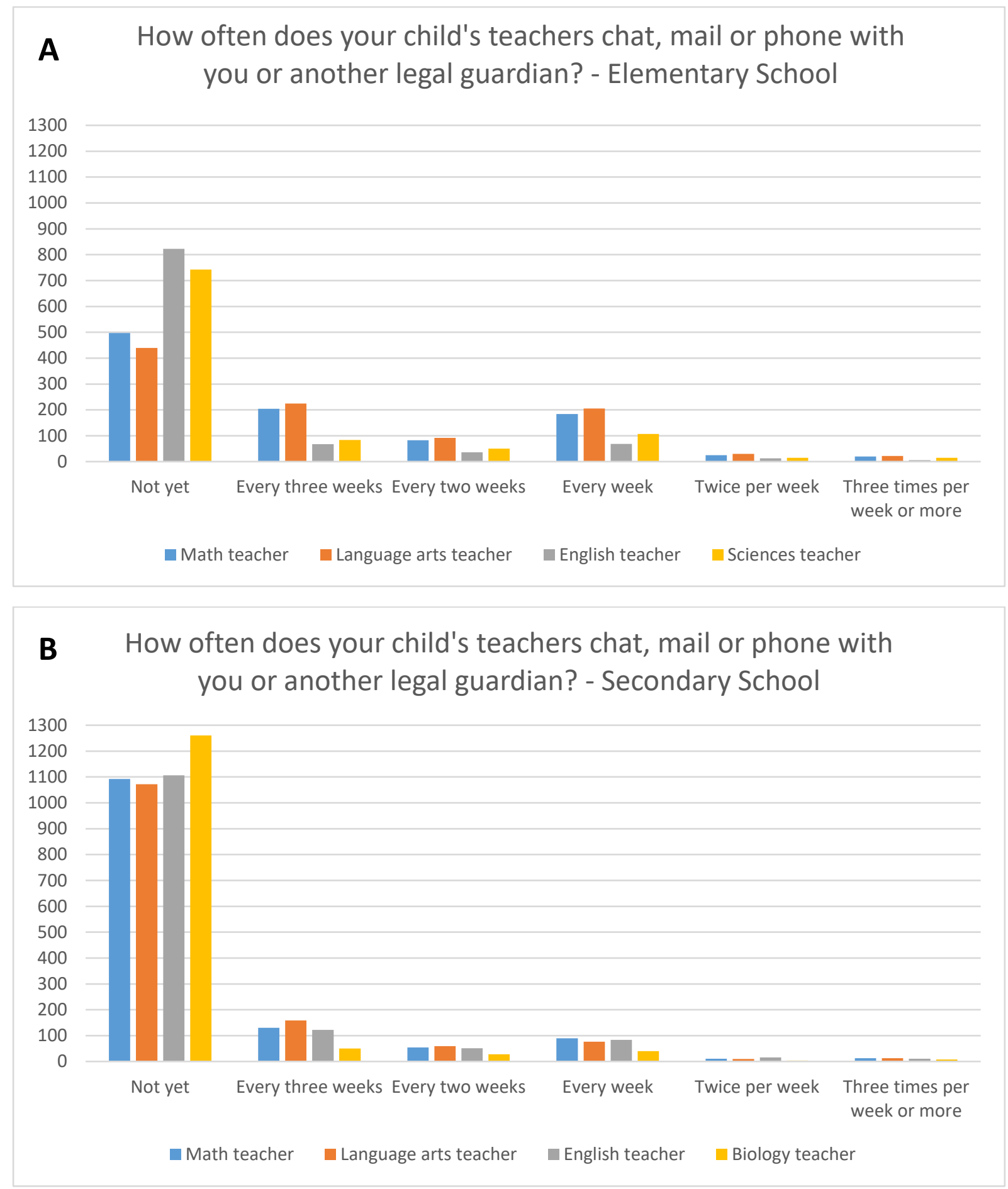

Figure S5.7. Frequencies of chatting, mailing or phoning with the parents or another legal guardian in elementary school (A) and secondary school (B). 

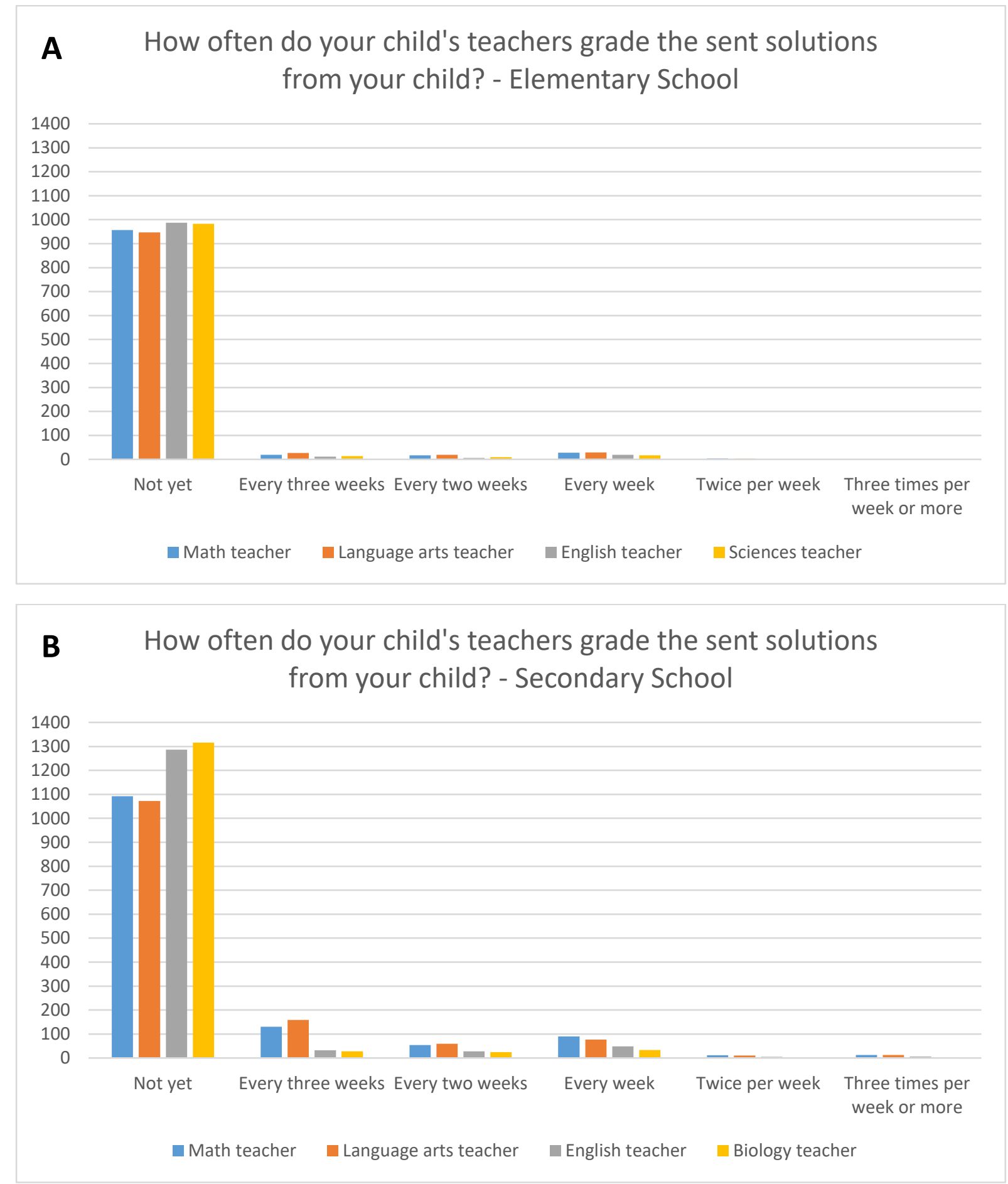

Figure S5.8. Frequencies of grading the task solutions in elementary school (A) and secondary school (B). 


\section{Supplement 6. Descriptive statistics for the elementary school sample}

\section{Table S6}

Means $(M)$, standard deviation (SD), internal consistencies ( $\alpha$ ) as well as bivariate correlations (above the diagonal parametric, below non-parametric) in the elementary school sample

\begin{tabular}{|c|c|c|c|c|c|c|c|c|c|c|c|c|c|c|c|c|c|c|c|c|c|c|c|c|c|c|}
\hline & $M$ & $S D$ & $\alpha$ & 1) & 2) & 3) & 4) & 5) & 6) & 7) & 8) & 9) & 10) & 11) & 12) & 13) & 14) & 15) & 16) & 17) & 18) & 19) & 20) & 21) & 22) & 23) \\
\hline \multicolumn{27}{|c|}{$\begin{array}{l}\text { Student outcomes during the school } \\
\text { lockdown }\end{array}$} \\
\hline 1) Motivation ${ }^{b}$ & 2.68 & 1.13 & .91 & & .51 & .54 & .12 & .13 & .09 & .11 & .06 & .09 & .18 & .15 & -.31 & .42 & .19 & .16 & .02 & .03 & -.04 & -.06 & $<-.01$ & .03 & .04 & .03 \\
\hline $\begin{array}{l}\text { 2) Competent and independent } \\
\text { learning }{ }^{\text {b }}\end{array}$ & 3.08 & 1.05 & .85 & .50 & & .34 & .10 & .10 & $<.01$ & .06 & $<.01$ & .04 & .13 & .08 & -.27 & .36 & .41 & .29 & .14 & -.02 & -.07 & -.08 & .04 & .04 & -.06 & .02 \\
\hline 3) Learning Progress ${ }^{b}$ & 2.96 & 1.16 & & .52 & .33 & & .12 & .10 & .07 & .10 & .03 & .08 & .12 & .20 & -.12 & .22 & .17 & .16 & .09 & $<.01$ & -.04 & .10 & -.10 & -.03 & -.07 & -.10 \\
\hline \multicolumn{27}{|l|}{$\begin{array}{l}\text { Frequency of distant teaching } \\
\text { activities }\end{array}$} \\
\hline 4) Tasksc & $2.99^{\mathrm{a}}$ & 0.87 & .74 & .10 & .11 & .11 & & .50 & .39 & .39 & .10 & .25 & .36 & .32 & -.01 & .08 & .08 & .06 & $<-.01$ & -.03 & -.01 & -.12 & -.03 & .07 & -.04 & .14 \\
\hline 5) Task Solutions ${ }^{c}$ & $2.01^{a}$ & 1.21 & .88 & .10 & .09 & .07 & .43 & & .28 & .40 & .13 & .24 & .34 & .31 & $<-.01$ & .06 & .06 & .01 & $<.-01$ & .02 & -.02 & -.08 & -.04 & .03 & -.06 & .17 \\
\hline 6) Request Solutions ${ }^{c}$ & $2.09^{a}$ & 1.20 & .89 & .08 & $<.01$ & .07 & .34 & .24 & & .67 & .21 & 19 & .27 & .20 & -.02 & .04 & .04 & .04 & -.04 & .06 & .01 & -.05 &.-.09 & .07 & -.03 & .11 \\
\hline 7) Feedback ${ }^{c}$ & $1.78^{a}$ & 1.08 & .88 & .10 & .05 & .10 & .32 & .35 & .67 & & .22 & .24 & .37 & .31 & .03 & .04 & .06 & .09 & -.01 & .03 & $<-.01$ & -.09 & -.05 & .05 & -.03 & .11 \\
\hline 8) Grading ${ }^{c}$ & $1.12^{\mathrm{a}}$ & 0.48 & .90 & .05 & $<.01$ & .02 & .05 & .11 & .18 & .22 & & .05 & .06 & .05 & -.06 & .03 & $<.01$ & .03 & -.10 & .07 & .02 & $<-.01$ & -.08 & .02 & .03 & .04 \\
\hline 9) Video conference ${ }^{c}$ & $1.21^{\mathrm{a}}$ & 0.64 & .85 & .08 & .04 & .08 & .21 & .21 & .14 & .14 & .01 & & .40 & .21 & $<.01$ & -.01 & -.01 & $<-.01$ & -.02 & -.01 & .02 & -.06 & -.07 & .02 & -.01 & .02 \\
\hline 10) Communication Child ${ }^{c}$ & $1.63^{\mathrm{a}}$ & 0.98 & .88 & .16 & .10 & .12 & .30 & .24 & .23 & .30 & .03 & .28 & & .47 & -.03 & .06 & .06 & .03 & .02 & .04 & -.03 & -.18 & -.02 & .03 & -.02 & .07 \\
\hline 11) Communication Parent ${ }^{c}$ & $1.85^{\mathrm{a}}$ & 1.05 & .87 & .13 & .06 & .18 & .24 & .20 & .21 & .31 & .05 & .14 & .40 & & .03 & .03 & .04 & .06 & .05 & .02 & -.02 & -.10 & $<.01$ & .01 & -.02 & -.03 \\
\hline \multicolumn{27}{|l|}{ Student characteristics } \\
\hline 12) Negative emotionality & 3.98 & 1.21 & .83 & -.32 & -.26 & -.11 & $<-.01$ & $<.01$ & -.01 & .04 & -.05 & -.01 & -.04 & .05 & & -.29 & -.08 & -.07 & .02 & -.06 & $<.01$ & $<-.01$ & .05 & .01 & -.09 & -.04 \\
\hline 13) School Engagement ${ }^{d}$ & 4.07 & 1.18 & .79 & .41 & .35 & .20 & .10 & .04 & .03 & .02 & .03 & $<.01$ & .05 & .02 & -.28 & & .43 & .41 & .08 & $<-.01$ & -.03 & -.09 & -.01 & .04 & .03 & .02 \\
\hline 14) Math competencies ${ }^{d}$ & 4.76 & 1.51 & .97 & .18 & .40 & .16 & .08 & .06 & .03 & .05 & $<-.01$ & .03 & .05 & .02 & -.09 & .40 & & .39 & .12 & .04 & -.04 & -.07 & -.02 & -.01 & -.22 & $<.01$ \\
\hline
\end{tabular}




\begin{tabular}{|c|c|c|c|c|c|c|c|c|c|c|c|c|c|c|c|c|c|c|c|c|c|c|c|c|c|c|}
\hline 15) Language art competencies ${ }^{d}$ & 4.93 & 1.30 & .92 & .16 & .30 & .15 & .06 & .02 & .04 & .08 & .02 & .02 & .04 & .04 & -.07 & .41 & .37 & & .14 & -.02 & .01 & -.06 & $<.01$ & .05 & .05 & -.03 \\
\hline \multicolumn{27}{|l|}{ Social background } \\
\hline $\begin{array}{l}\text { 16) Highest school leaving } \\
\text { certificate }\end{array}$ & 0.80 & 0.40 & & .03 & .14 & .09 & $<-.01$ & $<.01$ & -.04 & -.01 & -.10 & $<.01$ & .02 & .06 & .02 & .07 & .11 & .14 & & .02 & -.03 & -.09 & -.04 & .18 & .02 & -.05 \\
\hline 17) Migration background & 0.07 & 0.26 & & .02 & -.01 & $<.01$ & -.05 & .02 & .07 & .05 & .06 & -.04 & .01 & $<.-01$ & -.06 & $<-.01$ & .04 & -.01 & .02 & & $<.01$ & .03 & $<-.01$ & .02 & $<.01$ & $<-.02$ \\
\hline 18) Child has an own room & 0.87 & 0.33 & & .04 & .07 & .04 & -.01 & .02 & $\begin{array}{l}<- \\
.01\end{array}$ & $\begin{array}{l}<- \\
.01\end{array}$ & -.05 & $\begin{array}{l}<- \\
.01\end{array}$ & .03 & $<-.01$ & -.02 & .03 & .04 & $<-.01$ & .03 & $<-.01$ & & -.07 & .02 & .14 & .02 & .06 \\
\hline 19) Child has a computer/tablet & 0.88 & 0.32 & & .07 & .08 & .05 & .12 & .07 & .05 & .10 & $<.01$ & .03 & .14 & .09 & .01 & .09 & .08 & .06 & .09 & -.03 & -.07 & & -.03 & .09 & -.05 & .10 \\
\hline \multicolumn{27}{|l|}{ Child's and parent's gender and age } \\
\hline 20) Parent's gender & 1.85 & 0.35 & & $<-.01$ & .04 & .09 & -.01 & -.04 & -.07 & -.02 & -.07 & -.07 & $<.01$ & .01 & .05 & -.02 & -.02 & $<-.01$ & -.04 & $<-.01$ & -.02 & .03 & & -.20 & .07 & -.03 \\
\hline 21) Parent's age & 40.85 & 5.13 & & .04 & .04 & -.01 & .07 & .03 & .07 & .03 & -.02 & .03 & .05 & $<.01$ & $<.01$ & .02 & -.01 & .06 & .18 & .01 & -.15 & -.09 & -.16 & & .03 & .20 \\
\hline 22) Child's gender & 1.47 & 0.50 & & .04 & -.06 & -.07 & -.03 & -.06 & -.01 & -.03 & .04 & .02 & $<-.01$ & -.04 & -.09 & .04 & -.23 & .05 & .02 & $<.01$ & -.02 & .05 & .07 & .04 & & -.04 \\
\hline 23) Child's age & 8.31 & 1.26 & & .03 & .03 & -.10 & $.15-$. & .20 & .10 & .08 & .05 & .03 & .06 & -.06 & -.04 & .02 & .02 & -.01 & -.04 & -.02 & -.07 & -.10 & -.04 & .19 & -.03 & \\
\hline
\end{tabular}

Notes. $N=960-1063$. Highest school leaving certificate: $0=$ no or vocational track school leaving certificate, $1=$ academic track school leaving certificate; Child

has an own room: $0=$ no, 1 = yes; Child has a computer/tablet: $0=$ no, 1 = yes; Gender: $0=$ male, $1=$ female; migration background: $0=$ no, $1=$ yes.

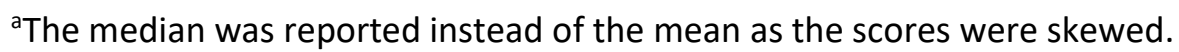

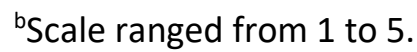

'Scale ranged from 1 to 6.

dScale ranged from 1 to 7.

Correlations: $r<.04 p<.05, r<.05 p<.01,, r<.06 p<.001$. 


\section{Supplement 7. Descriptive statistics for the secondary school sample}

\section{Table S7}

Means (M), standard deviation (SD), internal consistencies ( $\alpha$ ) as well as bivariate correlations (above the diagonal parametric, below non-parametric) in the secondary school sample

\begin{tabular}{|c|c|c|c|c|c|c|c|c|c|c|c|c|c|c|c|c|c|c|c|c|c|c|c|c|c|c|}
\hline & $M$ & $S D$ & $\alpha$ & 1) & 2) & 3) & 4) & 5) & 6) & 7) & 8) & 9) & 10) & 11) & 12) & 13) & 14) & 15) & 16) & 17) & 18) & 19) & 20) & 21) & 22) & 23) \\
\hline \multicolumn{27}{|l|}{$\begin{array}{l}\text { Student outcomes during the } \\
\text { school lockdown }\end{array}$} \\
\hline 1) Motivation & 2.73 & 1.08 & .88 & & .52 & .63 & .13 & .15 & .16 & .25 & .09 & .09 & .23 & .06 & -.30 & .40 & .13 & .19 & .04 & .05 & $<.01$ & -.09 & $<.01$ & .04 & .17 & .12 \\
\hline $\begin{array}{l}\text { 2) Competent and independent } \\
\text { learning }{ }^{\text {b }}\end{array}$ & 3.24 & 1.02 & .86 & .50 & & .28 & .04 & .07 & .09 & .15 & .05 & .10 & .14 & -.03 & -.31 & .36 & .21 & .31 & .09 & .02 & -.07 & -.09 & .03 & .08 & .14 & .31 \\
\hline 3) Learning Progress ${ }^{b}$ & 2.72 & 1.13 & & .61 & .27 & & .15 & .16 & .18 & .25 & .07 & .12 & .24 & .13 & -.13 & .28 & .10 & .14 & .02 & .06 & .01 & -.03 & .05 & -.02 & .08 & .01 \\
\hline $\begin{array}{l}\text { Frequency of distant teaching } \\
\text { activities }\end{array}$ & & & & & . & & & & & & & & & & & & & & & & & & & & & \\
\hline 4) Tasksc & $3.79^{a}$ & 0.73 & .74 & .13 & .04 & .15 & & .53 & .50 & .40 & .13 & .24 & .25 & .09 & .01 & .09 & .06 & .07 & -.03 & .01 & -.01 & -.02 & -.03 & -.03 & .04 & -.07 \\
\hline 5) Task Solutionsc & $2.99^{a}$ & 1.13 & .79 & .16 & .05 & .16 & .52 & & .35 & .48 & .14 & .33 & .30 & .14 & .01 & .07 & .07 & .05 & -.05 & -.07 & -.02 & $<-.01$ & -.05 & $<.01$ & .05 & -.10 \\
\hline 6) Request Solutionsc & $3.09^{a}$ & 1.18 & .84 & .16 & .09 & .18 & .50 & .36 & & .58 & .17 & .21 & .34 & .09 & -.01 & .04 & -.03 & .05 & $<.01$ & .02 & -.03 & .04 & -.06 & .07 & .01 & .11 \\
\hline 7) Feedback c & $2.31^{a}$ & 1.18 & .82 & .24 & .15 & .24 & .37 & .46 & .56 & & .26 & .33 & .49 & .22 & -.06 & .10 & .01 & .06 & -.05 & -.03 & -.01 & -.04 & -.02 & .04 & .05 & .05 \\
\hline 8) Gradingc & $1.18^{a}$ & 0.62 & .93 & .08 & .03 & .04 & .07 & .08 & .10 & .21 & & .14 & .19 & .16 & -.03 & .05 & -.01 & -.02 & -.07 & .03 & .04 & -.02 & -.01 & $<.01$ & .04 & .11 \\
\hline 9) Video conference ${ }^{c}$ & $1.62^{\mathrm{a}}$ & 0.95 & .78 & .09 & .12 & .10 & .16 & .28 & .18 & .30 & .08 & & .42 & .19 & .01 & .02 & .05 & .03 & .01 & -.05 & .01 & -.03 & -.05 & .04 & .01 & -.01 \\
\hline 10) Communication Childc & $2.15^{a}$ & 1.26 & .85 & .22 & .12 & .23 & .21 & .25 & .32 & .47 & .12 & .35 & & .26 & $<-.01$ & .08 & -.01 & .08 & -.03 & -.03 & -.03 & -.08 & -.04 & .02 & .05 & .07 \\
\hline 11) Communication Parent ${ }^{c}$ & $1.38^{\mathrm{a}}$ & 0.77 & .85 & .03 & -.06 & .11 & .05 & .10 & .04 & .16 & .06 & .14 & .23 & & .05 & -.02 & -.01 & -.04 & -.08 & -.01 & .06 & -.01 & .02 & -.06 & -.01 & -.13 \\
\hline \multicolumn{27}{|l|}{ Student characteristics } \\
\hline 12) Negative emotionality ${ }^{d}$ & 3.66 & 1.27 & .84 & -.29 & -.31 & -.12 & -.02 & .01 & -.02 & -.05 & -.05 & .01 & $<-.01$ & .08 & & -.24 & -.08 & -.11 & -.01 & -.05 & -.01 & .02 & .01 & -.07 & -.20 & -.17 \\
\hline 13) School Engagement ${ }^{d}$ & 4.10 & 1.25 & .83 & .40 & .36 & .27 & .08 & .06 & .05 & .11 & .03 & .02 & .09 & -.03 & -.24 & & .36 & .48 & .09 & .00 & $<.01$ & -.04 & .05 & .03 & .26 & .07 \\
\hline 14) Math competencies ${ }^{d}$ & 4.51 & 1.49 & .98 & .13 & .21 & .08 & .05 & .07 & -.03 & .03 & $<.01$ & .06 & $<-.01$ & .01 & -.08 & .35 & & .28 & .11 & -.06 & -.04 & .02 & -.05 & .02 & -.16 & -.05 \\
\hline 15) Language art competencies ${ }^{d}$ & 4.78 & 1.34 & .93 & .19 & .33 & .15 & .04 & .04 & .05 & .07 & -.02 & .06 & .11 & -.04 & -.14 & .47 & .27 & & .16 & .01 & .00 & -.05 & -.01 & .05 & .15 & .05 \\
\hline
\end{tabular}

Online Supplemental Material, [names blinded for review], Zeitschrift für Pädagogische Psychologie -75 


\section{Social background}

16) Highest school leaving certificate

\section{7) Migration background}

$\begin{array}{ll}0.77 & 0.42 \\ 0.07 & 0.25 \\ 0.94 & 0.24 \\ 0.96 & 0.19\end{array}$

$\begin{array}{lllllllll}.05 & .10 & .03 & -.02 & -.04 & <.01 & -.04 & -.06 & .08\end{array}$

$\begin{array}{lll}.00 & -.07 & -.01\end{array}$

$\begin{array}{lll}.10 & .11 & .16\end{array}$

$\begin{array}{lllllll}-.01 & -.05 & -.05 & -.11 & .17 & <.01 & -.04\end{array}$

18) Child has an own room

$\begin{array}{lllllll}.04 & .02 & .05 & .01 & -.06 & .01\end{array}$

$<-.01 \quad .07<-.01<.01 \quad 02 \quad .03 \quad .01 \quad-$.

$\begin{array}{llll}<-.01 & -.06 & .02 & -.01\end{array}$

$.12-.04$

19) Child has a computer/tablet

Child's and parent's gender and

age

\begin{tabular}{|c|c|c|c|c|c|c|c|c|c|c|c|c|c|c|c|c|c|c|c|c|c|c|c|c|c|}
\hline 20) Parent's gender & 1.83 & 0.37 & $<-.01$ & .03 & .05 & -.02 & -.05 & -.06 & -.01 & .02 & -.06 & -.03 & .01 & .02 & .05 & -.05 & -.01 & -.11 & .03 & .02 & .01 & & -.23 & .09 & $<-.01$ \\
\hline 21) Parent's age & 45.01 & 5.28 & .04 & .08 & -.03 & -.03 & $<.01$ & .07 & .06 & .01 & .08 & -.04 & -.08 & -.08 & .04 & .03 & .06 & .16 & -.08 & -.13 & -.05 & -.21 & & -.02 & .27 \\
\hline 22) Child's gender & 1.48 & 0.50 & .17 & .13 & .08 & .04 & .05 & .01 & .05 & .03 & .03 & .05 & -.01 & .20 & .26 & -.16 & .16 & $<.01$ & .01 & .02 & -.03 & .09 & $<-.01$ & & -.03 \\
\hline 23) Child's age & 12.55 & 1.86 & .11 & .31 & $<-.01$ & -.06 & -.09 & .13 & .07 & .14 & .02 & .09 & -.16 & -.16 & .04 & -.04 & .05 & -.05 & .04 & -.06 & -.06 & .01 & .26 & -.04 & \\
\hline
\end{tabular}

Notes. $N=1273$ - 1456 . Highest school leaving certificate: $0=$ no or vocational track school leaving certificate, $1=$ academic track school leaving certificate;

Child has an own room: $0=$ no, $1=$ yes; Child has a computer/tablet: $0=$ no, $1=$ yes; Gender: $0=$ male, $1=$ female; migration background: $0=$ no, $1=$ yes.

${ }^{a}$ The median was reported instead of the mean as the scores were skewed.

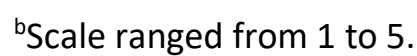

'Scale ranged from 1 to 6.

dScale ranged from 1 to 7.

Correlations: $r<.04 p<.05, r<.05 p<.01, r<.06 p<.001$ 
Supplement 8. . Model fit of structure equation models without student characteristics and demographics as additional predictors

\section{Table S8}

Model Fit indices and inter-correlations between exogenous variables for structure equation models regressing distant teaching activities on students' academic outcomes during the school lockdown without student characteristics and demographics as additional predictors for the total sample (All), elementary school (ES) and secondary school (Sec)

\begin{tabular}{rlllllll}
\hline Sample & $\chi^{2}$ (df) & RMSEA (CI 90\%) & CFI & TLI & $r_{\text {resM x resc }}$ & $r_{\text {resM x resL }}$ & $r_{\text {resc }}$ resL \\
\hline All & $860.29(541)$ & $.015(.013-.017)$ & .992 & .990 & .642 & .625 & .456 \\
ES & $618.00(541)$ & $.012(.006-.016)$ & .997 & .996 & .568 & .579 & .388 \\
Sec & $681.35(541)$ & $.013(.010-.016)$ & .992 & .990 & .639 & .654 & .347
\end{tabular}

Notes. resM = residual factor motivation. resC = residual factor competent and independent learning. res $\mathrm{L}=$ residual learning process $. \mathrm{df}=$ degrees of freedom $. \mathrm{Cl}=$ Confidence Interval 


\section{Supplement 9. Results of structure equation models without student characteristics and demographics as additional predictors}

\section{Table S9}

Path weights of the structure equation model (SEM) regressing distant teaching activities regressed on students' motivation, competent and independent learning, and learning progress during the school lockdown

\begin{tabular}{|c|c|c|c|c|c|c|c|c|c|c|c|c|c|c|c|c|c|c|}
\hline \multirow{3}{*}{$\begin{array}{l}\text { Model } \\
\text { Path weight, SE }\end{array}$} & \multicolumn{6}{|c|}{ Motivation } & \multicolumn{6}{|c|}{ Competent and independent learning } & \multicolumn{6}{|c|}{ Learning Progress } \\
\hline & \multicolumn{2}{|c|}{ All } & \multicolumn{2}{|c|}{ ES } & \multicolumn{2}{|c|}{ Sec } & \multicolumn{2}{|c|}{ All } & \multicolumn{2}{|c|}{ ES } & \multicolumn{2}{|c|}{$\mathrm{Sec}$} & \multicolumn{2}{|c|}{ All } & \multicolumn{2}{|c|}{ ES } & \multicolumn{2}{|c|}{ Sec } \\
\hline & $\beta$ & $S E$ & $\beta$ & $S E$ & $\beta$ & $S E$ & $\beta$ & $S E$ & $\beta$ & $S E$ & $\beta$ & $S E$ & $\beta$ & $S E$ & $\beta$ & $S E$ & $\beta$ & $S E$ \\
\hline Tasks & .051 & .027 & -.006 & .049 & $.198 * * *$ & .044 & $.072 * *$ & .024 & .064 & .060 & .063 & .040 & $.103^{*}$ & .041 & -.012 & .064 & $.177^{*}$ & .082 \\
\hline Task Solutions & $.107^{* * *}$ & .029 & $.118^{*}$ & .050 & .003 & .044 & .036 & .025 & $.121^{* * *}$ & .033 & -.037 & .047 & .038 & .026 & .105 & .064 & .032 & .075 \\
\hline Request Solutions & .033 & .031 & -.013 & .046 & $-.107^{*}$ & .043 & -.039 & .021 & -.052 & .039 & $-.086 * * *$ & .022 & .033 & .035 & .000 & .070 & -.031 & .078 \\
\hline Feedback & $.089 *$ & .044 & $.206^{* * *}$ & .058 & $.286 * * *$ & .033 & $.089 * * *$ & .025 & $.161 * *$ & .053 & $.220 * * *$ & .034 & $.096 *$ & .040 & $.200 * * *$ & .062 & $.235 * * *$ & .064 \\
\hline Grading & .011 & .025 & -.038 & .080 & $-.090 * *$ & .033 & -.039 & .040 & $-.130 *$ & .061 & -.046 & .046 & $-.050^{*}$ & .019 & -.119 & .073 & $-.186 * * *$ & .048 \\
\hline Video & -.044 & .026 & -.044 & .053 & -.067 & .071 & .024 & .026 & -.058 & .066 & .067 & .037 & -.017 & .028 & .050 & .063 & -.047 & .050 \\
\hline Com. Child & $.204 * * *$ & .031 & $.181 * * *$ & .038 & $.190 *$ & .081 & $.160 * * *$ & .027 & $.159 * * *$ & .035 & $.114^{* * *}$ & .032 & $.136 * * *$ & .025 & .007 & .049 & $.172 *$ & .070 \\
\hline Com. Parent & -.016 & .014 & .057 & .057 & .007 & .034 & $-.107 * * *$ & .026 & -.030 & .074 & $-.133 * * *$ & .031 & $.136 * * *$ & .017 & $.185^{* * *}$ & .050 & $.106^{*}$ & .042 \\
\hline $\mathrm{R}^{2}$ & .11 & & .10 & & .163 & & .05 & & .056 & & .067 & & .12 & & .08 & & .169 & \\
\hline
\end{tabular}

Notes. All = total sample; ES = Elementary school; Sec = Secondary School; Tasks = Sending Tasks; Tasks Solutions = Sending Task Solutions; Request Solutions = Requesting

students' solutions; Feedback $=$ Providing feedback on students' solutions; Video $=$ Teaching via videoconference; Com. Child $=$ Student-teacher communication; Com. Parent $=$

parent-teacher communication. ${ }^{*} p<.05, * * p<.01, * * * p<.001$. 